\title{
Systematic Characterization and Analysis of Resistance from Conductors and Electrodes for Solid Oxide Fuel Cells
}

Alec Hinerman

Follow this and additional works at: https://researchrepository.wvu.edu/etd

\section{Recommended Citation}

Hinerman, Alec, "Systematic Characterization and Analysis of Resistance from Conductors and Electrodes for Solid Oxide Fuel Cells" (2018). Graduate Theses, Dissertations, and Problem Reports. 5809. https://researchrepository.wvu.edu/etd/5809

This Thesis is protected by copyright and/or related rights. It has been brought to you by the The Research Repository @ WVU with permission from the rights-holder(s). You are free to use this Thesis in any way that is permitted by the copyright and related rights legislation that applies to your use. For other uses you must obtain permission from the rights-holder(s) directly, unless additional rights are indicated by a Creative Commons license in the record and/ or on the work itself. This Thesis has been accepted for inclusion in WVU Graduate Theses, Dissertations, and Problem Reports collection by an authorized administrator of The Research Repository @ WVU. For more information, please contact researchrepository@mail.wvu.edu. 


\title{
Systematic Characterization and Analysis of Resistance from Conductors and Electrodes for Solid Oxide Fuel Cells
}

\author{
Alec Hinerman \\ Thesis submitted \\ at West Virginia University \\ Masters of Science in \\ Mechanical Engineering \\ Yun Chen, Ph.D., Chair \\ Xueyan Song, Ph.D \\ Jacky Prucz, Ph.D
}

to the College of Engineering and Mineral Resources

in partial fulfillment of the requirements for the degree of

Department of Mechanical and Aerospace Engineering

Morgantown, West Virginia

May 2018

Keywords: Solid oxide fuel cell, thin films, ionic conductivity

Copyright 2018 Alec Hinerman 


\begin{abstract}
Systematic Characterization and Analysis of Resistance from Conductors and Electrodes for Solid Oxide Fuel Cells
\end{abstract}

\begin{abstract}
Alec Hinerman
Solid oxide fuel cells are all ceramic devices that generate electricity by direct electrochemical reactions of a fuel and oxidizer. Recent efforts are underway to reduce the operating temperature of solid oxide fuel cells which allow these devices to become more economically competitive. However, at decreased temperatures the resistance from key electrochemical processes greatly increases. The presented work encompasses the characterization and analysis of resistances from conductors and electrodes in solid oxide fuel cells. Ionic conductivity is a thermally activated process; therefore, the conductivity of the ion conducting phase must be improved for suitable operation at lower temperatures. Ionic transport along and across grain boundaries differ distinctly between polycrystalline solids with convention and nanometers sized grains. Ionic conductivity is often greater in the grain boundaries than compared to the grain bulk due to an accumulation of charge carriers. The Van der Pauw technique was leveraged in this worked to measure the conductivity of thin films with thicknesses on the order of nanometers. The results showed that ionic conduction within nanostructured thin films exceeds that of conventional polycrystalline materials. Furthermore, there is a need to identify the resistance that arises from individual electrochemical processes. Electrochemical impedance spectroscopy (EIS) is a technique regularly employed to analyze the resistance from electrochemical processes in the electrodes. Distribution of relaxation times has been applied to the impedance spectrum obtained through EIS. This high resolution plot allowed for the identification of resistances from individual electrochemical impedance processes. The resistances from gas diffusion in the anode and cathode, electrical charge transfer, and transport of ions through the ionic phase have been identified through distribution of relaxation times.
\end{abstract}




\section{Acknowledgment}

It would not have been possible to complete the master's program and thesis without the help and support from the kind people around me. I am very grateful to my research advisor Dr. Yun Chen. It has been a joy to work closely with you over the last two years. You have pushed me to develop my technical and soft skills. I am very appreciative of your help and direction. The guidance of Dr. Chen and Dr. Song were crucial to my experiments, thesis, and presentations.

I would like to thank Dr. Xueyan Song for her encouragement and patience over the last two years. Your support was essential to my success here. You have taught lessons and values that I will use to guide me on my future endeavors. Your devotion and enthusiasm to your research has been a joy to see.

I would also like to express my gratitude to Dr. Jacky Prucz for his input, suggestions, and contributions.

Finally, I would like to thank my family and friends for their support through this master's program. The morals and values that my parents have instilled into me have been critical to my progress in school and life. I would be here without their love and help. 


\section{Contents}

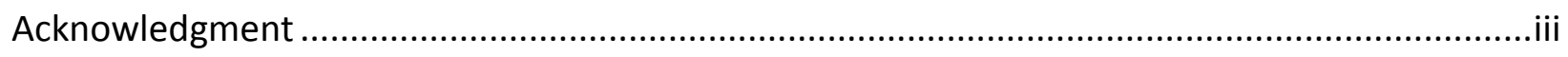

Table of Figures .............................................................................................................

Chapter 1: Background Review of Solid Oxide Fuel Cells ......................................................... 1

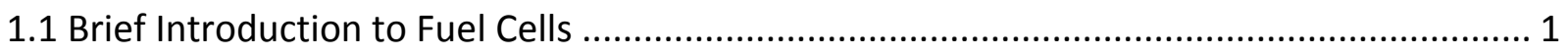

1.2 Background of Solid Oxide Fuel Cells ........................................................................... 1

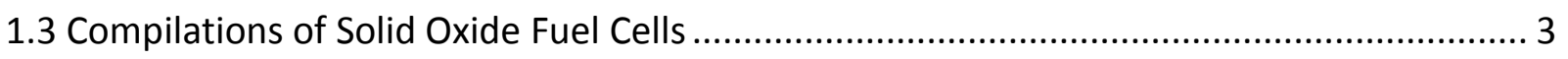

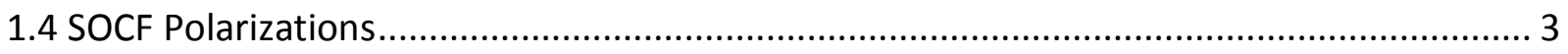

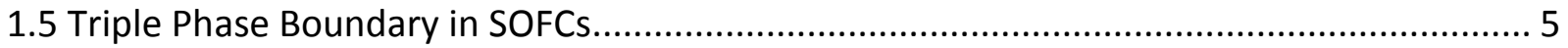

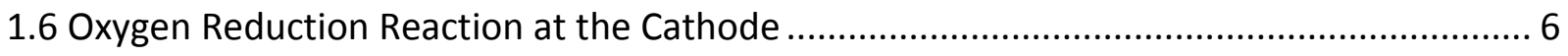

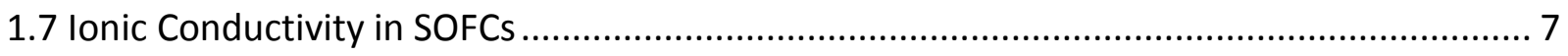

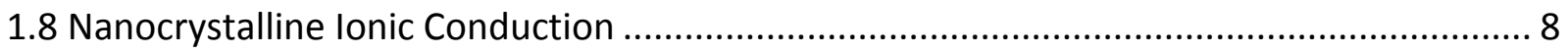

1.8.1 Nanocrystalline Oxygen Diffusivity.......................................................................... 10

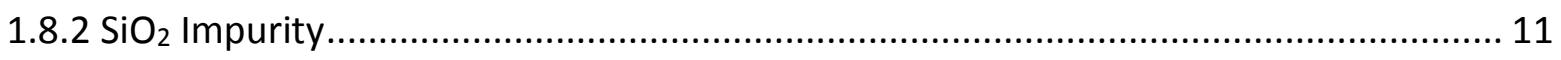

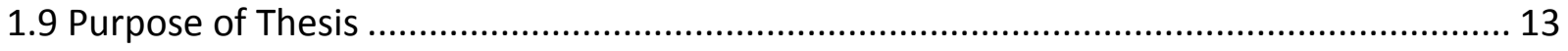

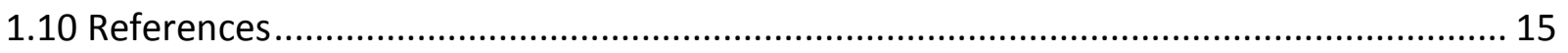

Chapter 2: Effects of Thin Film Yttrium-Stabilized Zirconia on lonic Conductivity...................... 18

2.1 Introduction to Ionic Conductivity of Yttrium Stabilized Zirconia .................................... 18

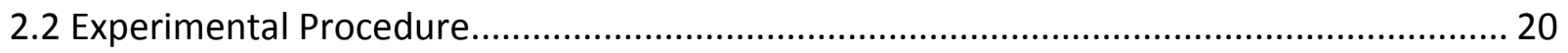

2.3 Electrical Conductivity of Yttrium-Stabilized Zirconia Thin Films...................................... 22

2.4 Summary of Results for Nanocrystalline Yttrium Stabilized Zirconia ................................. 26

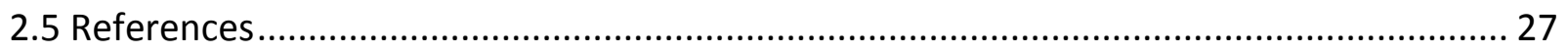

Chapter 3: Effects of Thin Film Zirconia Oxide on Ionic Conductivity ........................................ 28

3.1 Introduction to Nanocrystalline Conductivity .............................................................. 28

3.2 Experimental Procedure........................................................................................ 28

3.3 Electrical Conductivity of Zirconia Thin Films ……….................................................. 29

3.4 Summary of Results for Nanocrystalline Zirconia .......................................................... 31

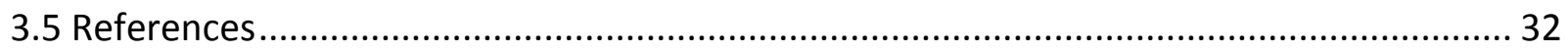

Chapter 4: Effects of Thin Film Manganese Doped Zirconia Oxide on Ionic Conductivity ............ 33

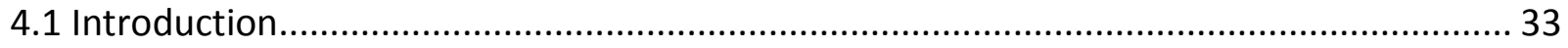

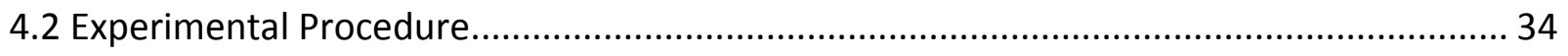


4.3 Electrical Conductivity of Manganese Doped Zirconia Thin Films ................................ 34

4.4 Summary of Results for Nanocrystalline Zirconia ...................................................... 37

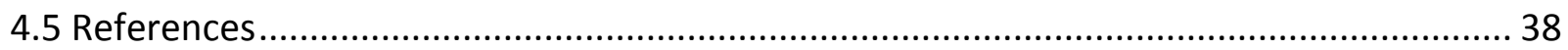

Chapter 5: Background of Electrochemical Impedance Spectroscopy and Distribution of

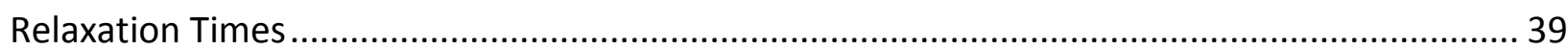

5.1 Introduction to Electrochemical Impedance Spectroscopy ........................................... 39

5.2 Background and Methodology to Distribution of Relaxation Times ................................ 41

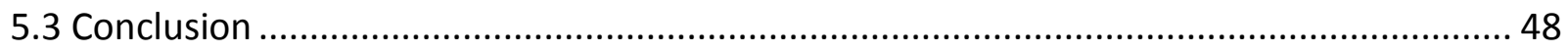

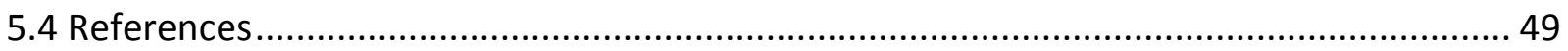

Chapter 6: Distribution of Relaxation Times in Solid Oxide Fuel Cells .................................... 50

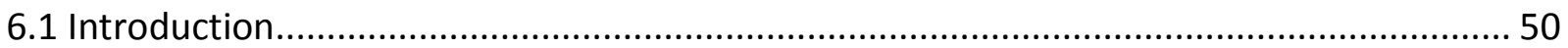

6.2 Methodology to Distribution of Relaxation Times ....................................................... 51

6.3 Results of the Distribution of Relaxation Times ........................................................... 52

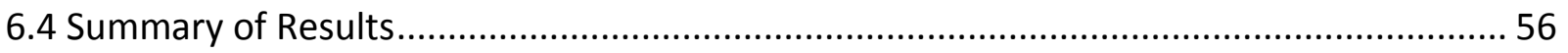

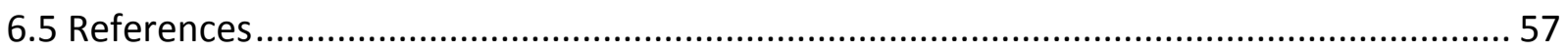

Chapter 7: Effect of Electrode Modifications Analyzed by Distribution of Relaxation Times ...... 58

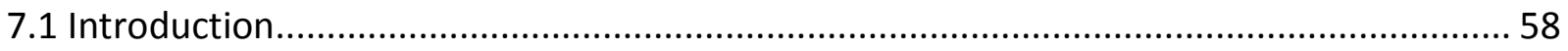

7.2 Methodology to Distribution of Relaxation Times..................................................... 58

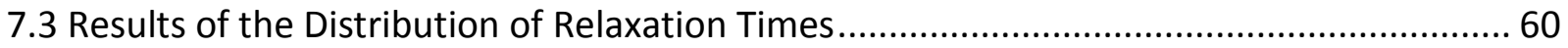

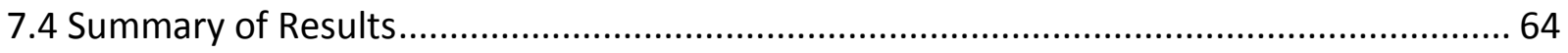

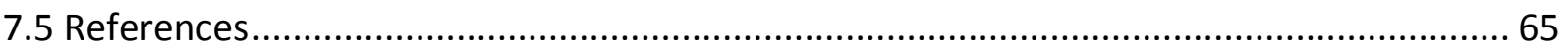

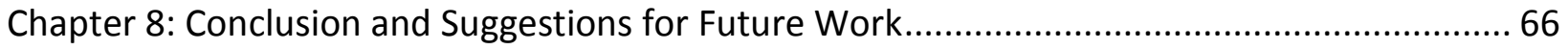

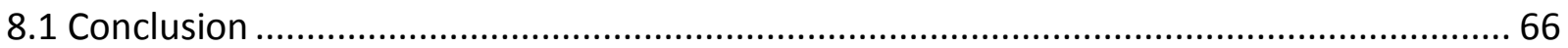

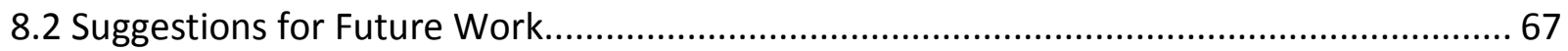




\section{Table of Figures}

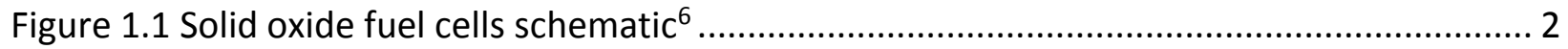

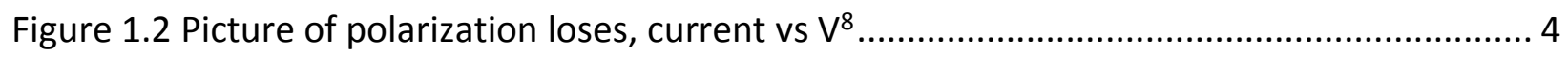

Figure 1.3 Triple phase boundary in solid oxide fuel cell cathode. ........................................ 6

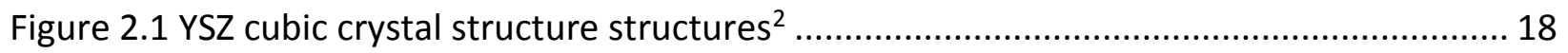

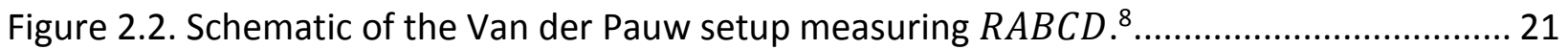

Figure 2.3. Electrical conductivity of thin films on YSZ substrate as a function of temperature. 23

Figure 3.1. Electrical conductivity of zirconia oxide thin films as a function of temperature...... 29

Figure 4.1. Electrical conductivity of thin films on YSZ substrate as a function of temperature. 35

Figure 5.1. Nyquist Plot of a fuel cell with LSM cathode (Fuel Cell Material) at $750^{\circ} \mathrm{C} \ldots \ldots \ldots \ldots . . . . . .41$

Figure 5.2. Example showing the removal of inductance from the $Z^{\prime \prime}$ data in the high frequency

end.

Figure 5.3. Comparison between the untreated data and the smoothed and extended data.... 44

Figure 5.4. Distribution of Relaxation Times for LSM Cathode (Fuel Cell Materials) 45

Figure 6.1. Series of DRT measured at three different hydrogen partial pressures in the anode.

Figure 6.2. Comparison between DRT of varying oxygen partial pressure at $750^{\circ} \mathrm{C} \ldots \ldots \ldots \ldots \ldots \ldots . . . . . .54$

Figure 6.3. Comparison between DRT of varying oxygen partial pressure at $700^{\circ} \mathrm{C} \ldots \ldots \ldots \ldots \ldots . \ldots 5$

Figure 6.4. Series of DRT at three different operating temperatures. .................................. 56

Figure 7.1. Distribution of relaxation times with varying hydrogen partial pressures measured at $750^{\circ} \mathrm{C}$ and $700^{\circ} \mathrm{C}$.

Figure 7.2. Distribution of relaxation times with varying oxygen partial pressure at $750^{\circ} \mathrm{C}$ and $700^{\circ} \mathrm{C}$

Figure 7.3. Comparison of DRT between baseline and modified cell with a higher density of TPB at OCV.

Figure 7.4. Comparison of DRT between baseline and modified cell with a higher density of TPB at an applied currrent of $0.3 \mathrm{~A} / \mathrm{cm}^{2}$. 64 


\section{Chapter 1: Background Review of Solid Oxide Fuel Cells}

\subsection{Brief Introduction to Fuel Cells}

There is a need to provide abundant and sustainable energy to secure the future. Therefore, creative solutions are being innovated that focus on efficiency and reducing pollution. Fuel cells prove to be a promising technology that generates electricity by direct electrochemical conversion of fuel. Unlike heat engines, fuel cells are not limited by the Carnot cycle. Instead, reactants in fuel cells are electrochemically combined to produce electricity with high efficiencies and limited amount of environmentally damaging pollutants.

Fuel cells are characterized by the type of electrolyte employed. The electrolyte material determines the type and purity of the fuel, oxidant used, and operating temperature. Several established fuel cells currently exist: Proton Exchange Membrane Fuel Cell (PEMFC), Alkaline Fuel Cells (AFC), Direct Methanol Fuel Cell (DMFC), Phosphoric Acid Fuel Cell (PAFC), Molten Carbonate Fuel Cell (MCFC) and the Solid Oxide Fuel Cell (SOFC). Of those listed, significant research interest has focused on proton exchange membrane fuel cells and solid oxide fuel cells as these demonstrate the greatest promise for market application. It is currently estimated PEMFC have progressed further in development; however, the SOFC possess characteristics that give it significant advantages for market acceptance. ${ }^{1}$ PEMFC require expensive platinum catalysts driving up capital costs. PEMFC system complexity and costs are further increased because these cells must operate on high purity hydrogen or else cell degradation is accelerated. Furthermore, proton exchange membrane fuel cells only achieve electrical efficiencies of only 35-45\%.

Unlike PEMPC, solid oxide fuel cells may utilize a wide range of fuel such as hydrogen, biofuels, and hydrocarbons. Also, the devices have shown to reach fuel conversion efficiencies up to $60 \% .^{2}$ These devices have potential application in a wide range of operational uses such as power units in a vehicle or utility power generation. ${ }^{3}$ SOFCs operate at high temperatures ranging from $500-1,000^{\circ} \mathrm{C}$. These devices create high grade heat that which be wholly utilized, thus making them excellent candidates for combined heat and power systems. ${ }^{4,5}$

\subsection{Background of Solid Oxide Fuel Cells}

As shown in Figure 1.1, the general operation of a solid oxide fuel cell consists of the following steps: reduction of oxygen at the cathode, diffusion of the oxygen ions through a 
dense electrolyte, and oxidation of the fuel by oxygen ions at the anode. The electrical potential difference between the electrodes causes electrons to flow.

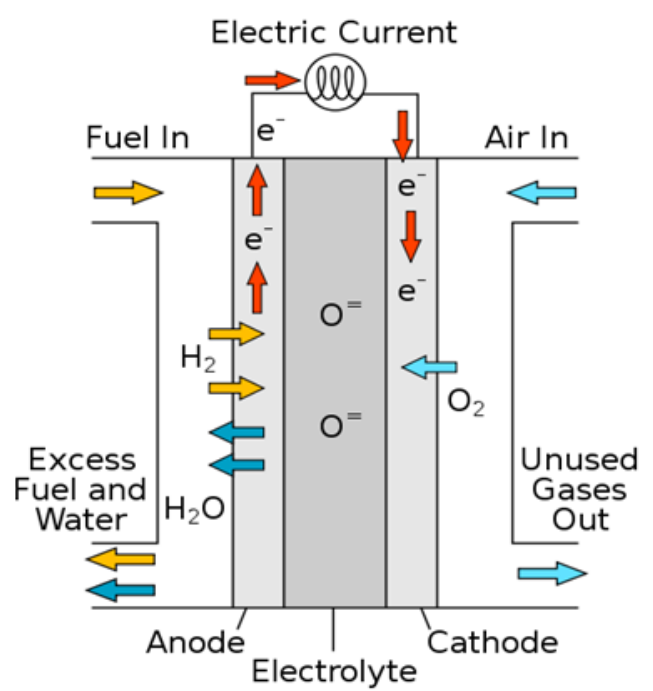

Figure 1.1 Solid oxide fuel cells schematic ${ }^{6}$

At the cathode surface, oxygen molecules adsorb and dissociate into oxygen atoms, become incorporated inside the oxide lattice, and are transferred to the solid electrolytes as ions. A thin electrolyte sandwiched between the cathode and anode conducts oxide ions between the two electrodes. Upon arrival to the anode, the oxide ions bond with the fuel source, thus releasing electrons to the circuit.

The cathode component is the site for oxygen reduction. The associated half reaction is written as: $\mathrm{O}_{2}(\mathrm{~g})+4 e^{-} \rightarrow 2 \mathrm{O}^{2-}$. Cathodes used in SOFC must possess high electrical conductivity, compatibility with other components, and catalytic activation for oxygen reduction. The modern day cathode is a heterogeneous mixture composed of yttria-stabilized zirconia (YSZ) and lanthanum strontium manganite (LSM). LSM exhibits a perovskite structure enabling the material to transport electrons while YSZ shuttles oxide ions. This combination of LSM/YSZ leads to an extended area of the triple phase boundaries (TPBs) increasing cell performance. $^{7}$

The name of the solid oxide fuel is derived by its use of solid state oxide materials as the electrolyte. Yttria-stabilized zirconia exhibits suitable ionic and mechanical properties and is therefore currently used as the electrolyte in present day SOFCs. Although YSZ does not exhibit the highest ionic conductivity compared to other ceramic oxides, it has excellent stability in 
both reducing and oxidizing environments making it a suitable candidate. With a thickness of only $10 \mu \mathrm{m}$ across, YSZ electrolytes are manufactured with a high density to ensure no electric current leakage between electrodes. ${ }^{2}$

Than anode is responsible for fuel oxidation. The following half reaction occurs in the anode: $\mathrm{H}_{2}(g)+\mathrm{O}^{2-} \rightarrow \mathrm{H}_{2} \mathrm{O}+2 e^{-}$. The SOFC anode, like the cathode, is electrically conductive. It consists of a cermet of YSZ and nickel, which catalyzes the fuel oxidation. The ionic conductor, YSZ, transports oxide ions and enables sites for oxidation of the fuel. The nickel component serves as a pathway for electron transfer into an external circuit.

\subsection{Compilations of Solid Oxide Fuel Cells}

Solid oxide fuel cells are lucrative products because of the wide source of fuels, high efficiencies, and low emissions. Currently, components of the fuel cell are costly and need improvements. For the technology to be competitive on the market, the cells must be cost competitive with the current options such as combustion engine generators. ${ }^{1,2}$ Furthermore, fuel cells must exhibit small degradation rates for the duration of its operational life. When cells are activated under operating conditions, the microstructure of the electrolyte and electrodes can change. These changes in structure are prominent between neighboring grains and at the boundaries of the electrolyte and electrode. The boundaries between phases are responsible for several reactions including sites for mass transfer, diffusion, and segregation of impurities. The performance of the cell depends on the structure of the components. Polarizations occur due to imperfections in the material, microstructure, and design of the fuel cell. The macroscopic performance of the solid oxide fuel cell is determined by the microscopic properties.

\subsection{SOCF Polarizations}

Polarization refers to the phenomena of displacing the electrode potential away from equilibrium by means of applying current, which reduces performance of solid oxide fuel cells from their expected output. Powers produced by fuel cells are a product of current density and voltage. Polarizations are a loss in voltage or overpotential, which is a function of current density. Under operating conditions, flaws in the fuel cell cause the voltage to deviate below the expected Nernst potential as more current is drawn from the cell. 
Polarization resistance $(\mathrm{Rp})$ is the transition resistance between the electrodes and the electrolyte. In other words, polarization resistance is an opposition to the flow of current in a voltaic cell that arises due to the chemical reactions at the electrodes. These chemical processes at the electrodes cause polarizations which reduce the electric potential across the cell. Polarizations can be broken into three categories: Ohmic, activation, and concentration.

In Figure 1.2, the cell voltage is shown as a function of current density. Ohmic contribution is due to resistance in materials and is represented as a linear relationship between voltage and current. Activation polarization is dominant at low current densities which arise from slow reaction kinetics. Concentration polarization is dominant at high current densities when mass transport limits the arrival of the reactants to their respective reaction sites. Polarizations create losses in voltage and reduce efficiency of solid oxide fuel cells.

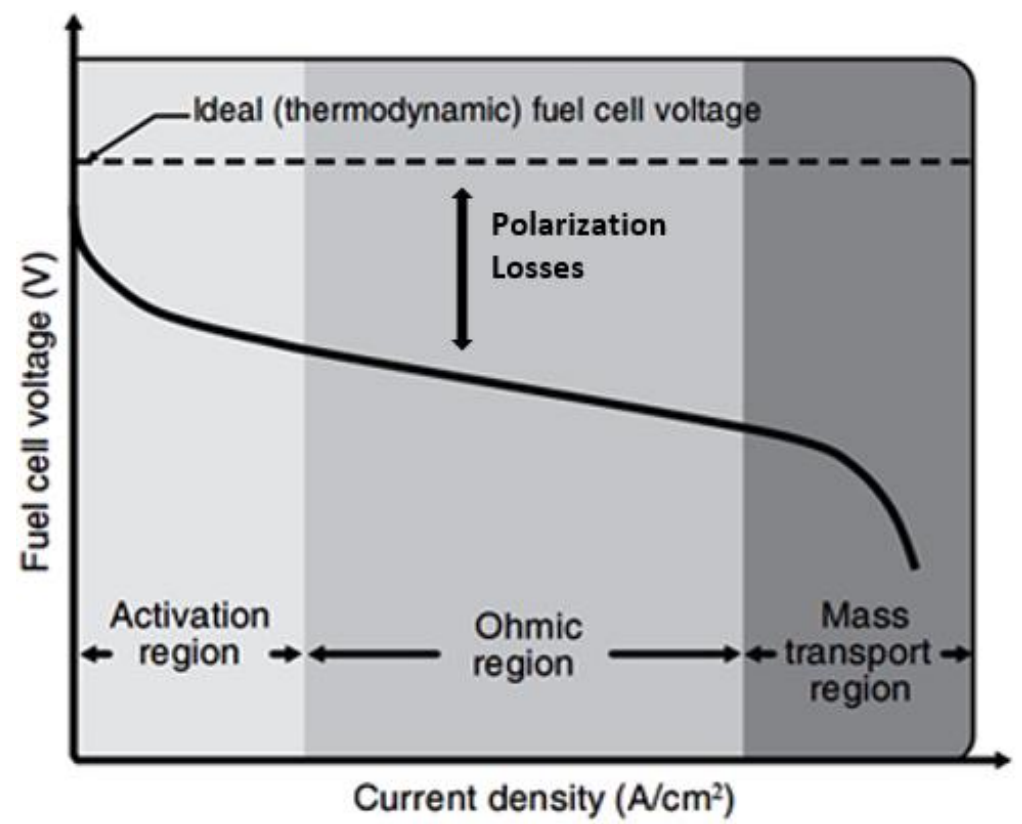

Figure 1.2 Picture of polarization loses, current vs $V^{8}$

Ohmic polarization refers to the resistance of ions and electrons that can be described by Ohm's Law. The relationship between voltage drop and current can be described by the resistivity of the material. The transport of oxide ions through the electrolyte are dictated by the YSZ resistivity. Movement of electrons via electrodes are governed by each the respective resistivity of each electrode. A significant contribution of the Ohmic resistance arises from the electrolyte and efforts in research have been employed to reduce the resistance from the 
electrolyte. The trend in reducing electrolyte thickness to a thin film has led to significant reductions in this Ohmic polarization. ${ }^{2}$ Electrolyte supported cells use thick YSZ layers as the cell backbone that lead to higher Ohmic resistivity compared to electrode supported cells. Ohmic resistances are smallest in electrode supported cells which enable the use of thin electrolytes. For such reasons, modern SOFC are anode supported and exhibit higher performance.

Concentration polarization arises from the resistance of the gaseous phases reaching their respective reactive sites. Fuel transports through the porous anode and must reach the nickel-YSZ interface where it reacts with oxide ions. Upon reduction at the anode, the products from fuel oxidation must also diffuse out of the anode backbone to be carried away in the fuel stream. Similarly, oxygen must diffuse through the porous cathode to reach the LSM-YSZ interface and react with electrons to form oxide ions. As shown in Figure 1.2, concentration polarizations are more pronounced at high current densities when large volumes of reactant must reach the reaction site. Concentration losses reflect the diffusion limitations of gas through the electrodes.

Activation energy refers to the energy barrier that must be surpassed for electrochemical processes to proceed. Upon reaching such energy barrier, electrode reactions exceed the spontaneous rate. Activation polarization refers to the overpotential or energy needed to drive the electrode reactions. Activation polarization is shown as a voltage drop due to slow reactions kinetics occurring at the electrode-electrolyte interfaces. Electron transfer between interfaces in the anode and cathode are thermally activated processes. At higher temperatures, more free energy is available leading to spontaneous reactions, thus reducing the activation polarization. The kinetics of oxidation and reduction are governed by the composition and microstructure of the electrodes. ${ }^{2}$

\subsection{Triple Phase Boundary in SOFCs}

The electrochemical reactions in solid oxide fuel cells only occur at catalytic sites in a region called the triple phase boundary (TPB). The TPB consists of joint areas of the gas phases, YSZ electrolyte, and respective electrolyte material. ${ }^{9}$ Electrode reactions at these sites consist of electron transfer between neutral and ionic species. 
In the anode, the triple phase boundary occurs at the junction of the ionic conductor YSZ, electronic conductor nickel, and the fuel. Fuel oxidation by oxygen ions follow the successive steps. The fuel becomes adsorbed onto the surface of YSZ or nickel in the anode. The adsorbed hydrogen diffuses to the triple phase boundary and becomes oxidized by ions from the electrolyte, releasing electrons into the external circuit.

\subsection{Oxygen Reduction Reaction at the Cathode}

Similarly, the existence of the triple phase boundary in the cathode proves crucial to the electrode's performance. At the cathode, the triple phase boundary consists of the convergence of oxygen gas, the YSZ electrolyte, and the LSM electrode. Oxygen reduction at the cathode is a complicated multistep process. The exact sequence of steps have been difficult to determine, but the overall processes has been theorized as follows:

1. Oxygen molecules become adsorbed onto the surface of the electron conductor.

2. Adsorbed oxygen molecules dissociate into atoms.

3. The dissociated adsorbed oxygen atoms migrate to triple phase boundary.

4. The oxygen atoms become ionized and transfer into the YSZ electrolyte. Variations of such reduction have been suggested, but the crucial component to the oxygen reduction is the proximity of the charge transfer either at or adjacent to the triple phase boundary. ${ }^{2}$ Oxygen reduction reactions are limited to the triple phase boundary sites. ${ }^{10}$

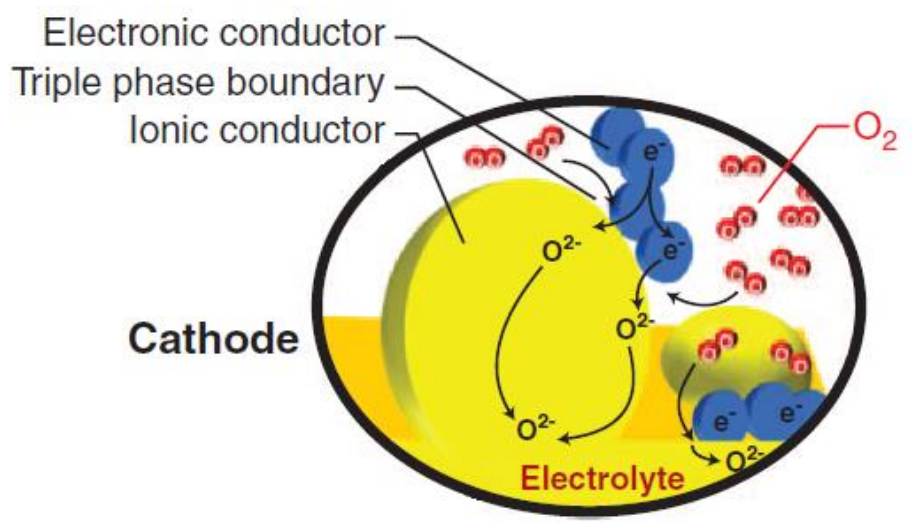

Figure 1.3 Triple phase boundary in solid oxide fuel cell cathode.

SOFC cathodes are composed of either a single phase or porous two phase composite matrix. The active region for oxygen reduction reactions in SOFC cathodes can be considerably improved with the addition of an ionic conductor to the electronic conductor. Electronically 
conductive lanthanum strontium magnate is combined with ionically conductive YSZ in this porous microstructure; therefor, extending the contact between the different conducting phases. For a single phase ionic-electronic mixed conductor, oxygen can be reduced at the surface of the cathode and transported through the electrode matrix to the cathode-electrolyte interface. Oxygen reduction reactions are catalyzed by the electronic conductor in the cathode. Lanthanum strontium magnate possess a perovskite crystal structure. Perovskite crystals are constructed in an $\mathrm{ABX}_{3}$ manner where " $\mathrm{A}$ " and " $\mathrm{B}$ " are two cations of different sizes. The B-site cation is a reducible transition metal, and the A-site cation is an alkaline earth metal. The X-site anion, oxide ion, is bonded to both cations. The octahedral symmetry of perovskite crystals exhibit metallic or semiconducting band structure at elevated temperatures; therefore, LSM possess high electronic conduction and is suitable for oxygen reduction reactions.

Oxygen reduction is thought to be most difficult reaction to activate in SOFCs operating at lower temperatures. ${ }^{11}$ Oxygen reduction in SOFC are quite complex and have been hypothetically broken into many steps. Oxygen molecules are believed to adsorb onto one or more of the solid surfaces, undergo a catalytic reduction, and become reduced to ionic spaces. Chemical adsorption, surface transport, and interface electrochemical kinetics all influence the rate of oxygen reduction reactions. ${ }^{12}$ Oxygen reduction reactions in the cathode most likely have several forces at work.

\subsection{Ionic Conductivity in SOFCs}

Conductivity of an oxide is a function of temperature, oxygen partial pressure, concentration of a dopant, and the microstructure. Ionic conductivity is related to charge carrier concentrations and mobility of the charge carrier. For a stabilized zirconia, such as YSZ, charge carriers are oxygen vacancies. ${ }^{13}$ lons move by ion hopping between near equivalent sights. The process is thermally activated; high temperatures are required to reach suitably high conductivity of YSZ in SOFCs. Oxygen atoms have a large radius leading to lower mobility. Conductivity can be maximized by selecting an appropriate doping element and an optimal concentration. With the addition of an aliovalent element to $\mathrm{ZrO}_{2}$, the disorder of $\mathrm{ZrO}_{2}$ will increase and allow for greater conductivity by the production of holes in the crystal lattice. The doping increases oxygen vacancies which provides more pathways for conduction of oxygen 
ions. For YSZ, temperatures around $900-1000^{\circ} \mathrm{C}$ are needed for a conductivity of $0.1 \mathrm{~S} / \mathrm{cm}$. In order to decrease operating temperatures in SOFC, the electrolyte and electrode conductance must increase to enhance gas and liquid reaction kinetics. ${ }^{14}$

The conductivity of multi crystal materials are influenced by the structure of the bulk grain and grain boundaries. Grain boundaries arise due to a mismatch lattices in the crystal, impurities, space charges, micro cracks, or a combination of all mentioned. Some polycrystalline materials have grain boundaries that proved rapid mass transportation comparted to the bulk grain. Impurities and defects such as holes tend to segregate to the grain boundaries to lower the strain of the bulk grain. Assuming that grains are of equal size and separated by a thin uniform grain boundary, a region is speculated to arise in polycrystalline materials where defects accumulate in the boundary between grains and creates a space charge region. If the defects in the space charge region exhibit high mobility, conductivity is expected to increase. ${ }^{14}$

Alternatively, it is suggested that grain boundaries of zirconia have lower charge carriers and insulating impurities such as $\mathrm{SiO}_{2}$ causing a higher resistance at the boundary. ${ }^{13} \mathrm{At}$ low temperatures, the conductivity of YSZ is dominated by the resistance of the ion transport across the grain boundary instead of the bulk grain. The higher resistance at low temperatures could be attributed to the formation of space charge zones. The ionic carrier in YSZ is the oxygen vacancies. At low temperatures, it has been suggested that oxygen vacancies are depleted near the grain boundary core due to an excess positive change in the grain. ${ }^{15,16}$ For positive space charge potentials, oxygen vacancies or electron holes are depleted in the grain boundaries and negative carriers, electrons, are enhanced. Grain boundary specific conductivity decreases rapidly with increasing grain size. The fluctuations in specific grain boundary conductivity correlated with microstructure should be analyzed to maximize electrolyte performance.

\subsection{Nanocrystalline Ionic Conduction}

Grain boundaries, ion diffusion, and defect properties influence electro ceramics performance. lonic transport along and across grain boundaries differ distinctly between polycrystalline solids with convention sizes and nanometers sized grains. Conductivity of nanocrystalline YSZ has been shown to be about one order of magnitude higher compared with 
microcrystalline samples. ${ }^{17}$ In polycrystalline thin films, ionic transport is controlled by grain boundaries and their interfaces. Highly doped materials, such as YSZ, contain extrinsic point defects. Such materials contain large concentrations of charged mobile carriers that accumulate in space charge regions. Diffusion of oxygen is often much greater than in the grain boundaries than the grain bulk due to high defect densities and high mobility in the grain boundary from interconnected excess free volume. ${ }^{14}$ It is suggested that space charge regions in the grains boundaries enhanced conditions for diffusion.

Mobile point defects in an ionic solid can be adsorbed at inner and outer interfaces. To mitigate strain and electrostatic energy of the bulk, charges species, impurities, and defects migrate to the grain boundaries. As defects of one charge accumulate at the grain boundary, the opposite charge defects accumulate in the grain bulk. This buildup in the interfacial region to accommodate the counter charge leads to the creation of a space charge region. ${ }^{18}$ In nanocrystalline materials, dimensions of the grain boundaries are comparable in size to that of the grains. Thus, a larger portion of atoms lie in the disordered region at the boundaries. Conductivity should increase with a high mobility in the space charge region. ${ }^{14}$

The width of the space charge region is described by the Debye screening length, where $C_{b}$ is the concentration of the carrier.

Equation $1 L_{D}=\left(\frac{\epsilon_{r} \epsilon_{O} k}{T q^{2} C_{b}}\right)^{1 / 2}$

As the diameter of the grains approach the Debye screening length, the defect density at the center of the grain does not revert back to neutral. Therefore, local charge neutrality is nowhere satisfied.

Heterostructures are composed of alternating conductive and insulated layers. These multilayered systems composed of alternating extrinsic ionic conductors and insulator can be manipulated to create a strain effect. Strain is introduced in the interface of the two different layers due to mismatch between lattice parameters and symmetries of the two tangent phases. The grains change structure in the vicinity of the phase boundary in order to maintain local internal equilibria. ${ }^{19}$ An accumulation of elastic energy at the interface region increases lattice misfit locations. The interface of heterostructures is strained due to a mismatch in symmetry of lattice parameters between the two phases. Such strain is alleviated by dislocations. An 
incoherent interface is formed between materials with disproportionate lattice parameters thus giving way to highly distorted surfaces. The dislocations result in a low packing density region compared to the bulk. The region can function as a pathway for faster ionic conduction compared to the grain interior. ${ }^{20,21,22}$

This induced strain in the boundary interface produces a space charge region which can positively affect ion transport. Mismatches between boundaries affect point defects by increasing the concentration of mobile charge carriers and increase carrier mobility. Improved mobility and higher concentrations of point defects can exhibit higher local ion diffusivity than the bulk components. ${ }^{19} \mathrm{~A}$ network of highly mobile dislocations can form fast conduction pathways.

\subsubsection{Nanocrystalline Oxygen Diffusivity}

As mentioned, grain boundaries possess high defect densities as well as high mobility of charge carriers. Furthermore, these characteristics positively influence oxygen diffusion. Nanocrystalline materials have shown to exhibit grain boundary diffusivity of several orders of manganite higher than bulk volume diffusivity. ${ }^{23} \mathrm{~A}$ study by Knoner et al. ${ }^{24}$ determined that the number of oxygen vacancies in the grain boundary exceeded the expected for nanocrystalline YSZ. In the vicinity of the grain boundary, stacking faults and distortions of adjacent lattices increase the concentration and aide the mobility of oxygen vacancies. Enhanced mobility of ions through the grains boundaries was also observed by a reduction in activation energy for grain boundary diffusivity compared to bulk diffusivity. It has been reported that oxygen incorporation was proven to be higher for surface morphologies of nanosize grains. ${ }^{25}$

Oxygen diffusivity $D$ is related to ionic conductivity $\sigma$ via the Nernst-Einstein relationship in Equation 2

Equation $2 \sigma=\frac{(\alpha e)^{2} n_{O^{2-}}}{f_{D} k_{B} T} D$

where e denotes that electronic charge, $\alpha$ the charge number of diffusing species, $\mathrm{n}_{\mathrm{o}-\text { - }}$ the atomic concentration of the diffusing oxygen ions, and $f_{D}$ a correlation factor. 


\subsection{2 $\mathrm{SiO}_{2}$ Impurity}

As stated earlier, solid oxide fuel cells subjected to operating conditions undergo structural transformations that degrade performance. This phenomena can occur in the form of diffusion and segregation of impurities to grain boundaries blocking the pathways for electrochemical reactions. The contamination of impurities in precursor materials proves to be of upmost importance in cell performance. Introduction of silica into the SOFC can occur during ceramic processing, sintering, and the operating system. ${ }^{26}$ Extensive studies have shown that starting materials containing $\mathrm{SiO}_{2}$ impurity form insulating films within the porous electrolyte which deters performance. It has been shown that small additions of only $0.2 \mathrm{wt} . \%$ silica can decrease grain boundary conductivity in YSZ by a factor of greater than $15 .^{27}$

In an electrochemical testing experiment performed by Y.L. Liu et $\mathrm{al}^{28}$., half cells composed of a Ni/YSZ cermet were evaluated after functioning at operating conditions. It was found that cells degraded at a rate of $10 \mathrm{~m} \Omega \mathrm{cm} 2$ per 1,000 hours at $1000^{\circ} \mathrm{C}$. To analyze changes in the microstructure of the half cells after the durability test, specimens were examined via TEM and SEM. The results revealed that a small proportion of contaminates, most likely introduced during the manufacturing process, were present and created a glass phase at the anode-electrolyte interphase. The study showed that impurities segregate and from a nanometer thin silicate glass phases along grain boundaries and interfaces between phases when the cell experienced high temperatures of $850-1000^{\circ} \mathrm{C}$.

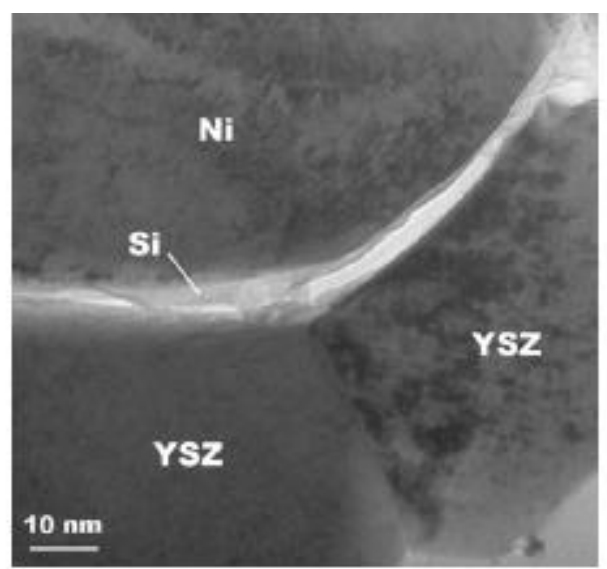

Figure 1.4. TEM image with Si-glass segregation at the grain boundaries between YSZ and Ni. ${ }^{29}$ 
Further experiments by $\operatorname{Liu}^{29}$ et al., examined the degree to which an anode/electrolyte interface and grain boundary can degraded as a function impurity concentration. Two commercial NiO powders containing varying levels of impurities were used for anode fabrication. The cells' durability were evaluated at temperatures of $850^{\circ} \mathrm{C}$ over 1,800 hours. Anodes containing a concentration of impurities in the order of hundreds of ppm exhibit structural degradation quicker than those with just of tens ppm of $\mathrm{SiO}_{2}$. SEM imaging revealed formation of glassy phases that form due to the high mobility of impurities during sintering. At high temperatures, these impurities are able to migrate and form a layer at the anode/electrolyte interface.

Furthermore, the polarization resistance of the anode with higher $\mathrm{SiO}_{2}$ concentration increased $85 \%$ compared to the resistance of the anode lacking $\mathrm{SiO}_{2}$ after 600 hours of testing. ${ }^{29}$ Significant amounts of the contamination phase amassed in the electrode/electrolyte interface and was present at the triple phase boundaries. The existence of this film blocks the activation reactions sites, reducing active areas of the TPB, and slows reaction kinetics. This accounts for the increase in polarization resistance of the anode with higher $\mathrm{SiO}_{2}$ concentration.

Conductivity of polycrystalline electrolytes are an important parameter when evaluating SOFCs. Total conductivity is governed by conductivity through both grain boundaries and grain interior; at lower temperatures, grain boundary conductivity significantly effects electrolyte performance. For doped zirconia, a major factor dominating the grain boundary conduction is the dissolution of $\mathrm{SiO}_{2}$ into zirconia lattice. ${ }^{26}$ Increasing the sintering temperature changes the viscosity and wetting nature of grain boundary phases to favorable conductions that promotes the proliferation of Si-containing phases along the grain boundaries.

The segregation of impurity silicon has been found to be grain-size dependent. ${ }^{27}$ For polycrystalline $\mathrm{YSZ}$ with $\mathrm{SiO}_{2}$ present, the total resistance is dictated by the grain boundary resistance. The boundary coverage of silicon can to be systematically varied by varying grain size. Insulating glassy films can be avoided with high purity precursors as well as small grain size. For grain sizes varying between 11.4 to $0.14 \mu \mathrm{m}$, the silicon coverage of grains decreases as grain size decreases. With grains of size $0.14 \mu \mathrm{m}$, no detectable silicon segregation was 
observed. The concentration of silica in the grain boundaries was low enough that a discrete film does not form.

\subsection{Purpose of Thesis}

The processes behind electrode overpotential losses remain an enormous focus of research. ${ }^{30}$ The emphasis to improve SOFCs electrodes are driven by the goal of lowering operating temperatures. Currently, SOFC systems require high operating temperature which drive up capital costs, increase performance degradation, and have slow start up times. Low temperature SOFCs can use cheaper interconnection components which reduce the overall cost. However at lower operating temperatures, activation polarization greatly contributes to the performance loss in solid oxide fuel cells due to slow reaction kinetics of oxygen reduction at the cathode and fuel oxidation at the anode. ${ }^{11}$ Oxygen reduction reactions are thermally activated processes with a high activation energy and slow reaction kinetics. Dissociation of hydrogen proceeds with faster kinetics than oxygen reduction at lower temperatures. Thus, the temperature dependence of activation polarization losses are attributed to oxygen reduction reactions at the cathode. In order to decrease the operating temperature, the conductance of the electrodes must increase.

The major steps dictating oxygen transport at the cathode are surface adsorption and bulk diffusions. ${ }^{31}$ Catalysts improve the surface exchange rate and improved ionic conductivity will increase oxygen reduction reactions. Cathode performance is highly dependent on the rates of the oxygen reduction reaction. Current research tries to determine the cause of slow reaction kinetics taking place at the cathode surface. Oxygen vacancies in the cathode material are crucial in influencing the ORR mechanisms. Oxygen vacancies act as a sink to adsorb oxygen and facilitate the oxygen reduction reaction. High concentrations of oxygen vacancies in the cathode surface increase the solid oxide fuel cell performance by presenting a high concentration of sites for oxygen incorporation. ${ }^{10}$ The properties of the SOFC cathode dictate key roles in determining the overall fuel cell performance. By utilizing polycrystalline ceramics of nanosize grains in the electrodes, one would aim to leverage the enhanced ionic conduction in the grain boundaries to improve electrode kinetics. 
The presented work encompasses the characterization and analysis of resistances and conductors for electrodes in solid oxide fuel cells. The Van der Pauw technique was leveraged in this worked to measure the conductivity of thin films with thicknesses on the order of nanometers. Furthermore, there is a need to identify the resistance that arises from individual electrochemical processes. Distribution of relaxation times (DRT) produces a high resolution plot which allows for the identification of individual electrochemical impedance processes. DRT has been applied to identify the resistance corresponding to processes in the electrodes. 


\subsection{References}

1. Elmer, T. T. A.-T. T.-. A novel SOFC tri-generation system for building applications. (2016).

2. Singhal, S. C. \& Kendall, K. T. A.-T. T.-. High-temperature solid oxide fuel cells : fundamentals, design, and applicatons. (2003).

3. Singhal, S. \& Pacific Northwest National Lab. WA (US), R. Solid oxide fuel cells for stationary, mobile, and military applications. TT -. Solid State lonics TA - 152, 405-410 (2002).

4. Rosendahl, L. A., Mortensen, P. V \& Enkeshafi, A. A. Hybrid Solid Oxide Fuel Cell and Thermoelectric Generator for Maximum Power Output in Micro-CHP Systems TT -. J. Electron. Mater. TA - 40, 1111-1114 (2011).

5. Zhang, H., Xu, H., Chen, B., Dong, F. \& Ni, M. Two-stage thermoelectric generators for waste heat recovery from solid oxide fuel cells TT -. Energy TA - 132, 280-288 (2017).

6. Solid oxide fuel cell. Wikipedia (2018). Available at: https://en.wikipedia.org/wiki/Solid_oxide_fuel_cell.

7. Chen, Y., Yang, L., Ren, F. \& An, K. Visualizing the Structural Evolution of LSM/xYSZ Composite Cathodes for SOFC by in-situ Neutron Diffraction TT -. Sci. Reports TA - 4, (2015).

8. NPTEL. Introduction to Fuel Cell technology - Overview. (2012). Available at: http://www.nptel.ac.in/courses/103102015/2.

9. Fehribach, J. \& O'Hayre, R. Triple Phase Boundaries in Solid-Oxide Cathodes. SIAM J. Appl. Math. 70, 510-530 (2009).

10. Chen, Y. et al. ChemInform Abstract: Advances in Cathode Materials for Solid Oxide Fuel Cells: Complex Oxides Without Alkaline Earth Metal Elements TT -. ChemInform TA - 47, no (2016).

11. Lee, K. T. \& Wachsman, E. D. Role of nanostructures on SOFC performance at reduced temperatures. MRS Bull. 39, 783-791 (2014).

12. Adler, S. B. Factors Governing Oxygen Reduction in Solid Oxide Fuel Cell Cathodes TT -. ChemInform TA - 35, no (2004).

13. Hui, S. (Rob) et al. A brief review of the ionic conductivity enhancement for selected oxide electrolytes TT -. J. power sources. TA - 172, 493 (2008).

14. Tuller, H. L. Ionic conduction in nanocrystalline materials. Solid State Ionics 131, 143-157 (2000).

15. Park, H. J. \& Kim, S. Space Charge Effects on the Interfacial Conduction in Sr-Doped Lanthanum Gallates: A Quantitative Analysis TT -. J. Phys. Chem. C TA - 111, 1490314910 (2007). 
16. Kim, S. \& Maier, J. On the Conductivity Mechanism of Nanocrystalline Ceria. TT -. ChemInform TA - 34, no (2003).

17. Kosacki, I., Suzuki, T., Petrovsky, V. \& Anderson, H. U. Electrical conductivity of nanocrystalline ceria and zirconia thin films TT -. Solid state ionics. TA - 136, 1225 (2001).

18. Peters, A., Korte, C., Hesse, D., Zakharov, N. \& Janek, J. Ionic conductivity and activation energy for oxygen ion transport in superlattices - The multilayer system CSZ (ZrO $2+$ $\mathrm{CaO})$ / Al 203 TT -. Solid State Ionics TA - 178, 67-76 (2007).

19. Korte, C., Peters, A., Janek, J., Hesse, D. \& Zakharov, N. Ionic conductivity and activation energy for oxygen ion transport in superlattices--the semicoherent multilayer system YSZ $\left(\mathrm{ZrO}_{2}+9.5\right.$ mol\% $\left.\mathrm{Y}_{2} \mathrm{O}_{3}\right) / \mathrm{Y}_{2} \mathrm{O}_{3} \mathrm{TT}$-. Phys. Chem. Chem. Phys. (Incorporating Faraday Trans. TA - 10, 4623-4635 (2008).

20. Fabbri, E., Pergolesi, D. \& Traversa, E. Ionic conductivity in oxide heterostructures: the role of interfaces TT -. Sci. Technol. Adv. Mater. TA - 11, 54503 (2010).

21. Karthikeyan, A., Chang, C.-L. \& Ramanathan, S. High temperature conductivity studies on nanoscale yttria-doped zirconia thin films and size effects. Appl. Phys. Lett. 89, 183116 (2006).

22. Chunyan, T. \& Siu-Wai, C. Electrical Conductivities of (CeO2)1-x(Y2O3)x Thin Films. J. Am. Ceram. Soc. 85, 2222-2229 (2004).

23. Bellino, M. G., Lamas, D. G. \& Walsöe de Reca, N. E. Enhanced Ionic Conductivity in Nanostructured, Heavily Doped Ceria Ceramics TT -. Adv. Funct. Mater. TA - 16, 107-113 (2006).

24. Knöner, G., Reimann, K., Röwer, R., Södervall, U. \& Schaefer, H.-E. Enhanced oxygen diffusivity in interfaces of nanocrystalline ZrO\&lt;sub\&gt;2\&lt;/sub\&gt; Y\&lt;sub\&gt;2\&lt;/sub\&gt;O\&lt;sub\&gt;3\&lt;/sub\&gt; Proc. Natl. Acad. Sci. 100, 3870 LP-3873 (2003).

25. Develos-Bagarinao, K., Kishimoto, H., De Vero, J., Yamaji, K. \& Horita, T. Effect of La0.6Sr0.4Co0.2Fe0.803- $\delta$ microstructure on oxygen surface exchange kinetics TT -. Solid State Ionics TA - 288, 6-9 (2016).

26. Zhang, T. S. et al. Different conduction behaviors of grain boundaries in SiO2-containing 8YSZ and CGO20 electrolytes TT -. Solid State Ionics TA - 177, 1227-1235 (2006).

27. Makoto, A. et al. Solute Segregation and Grain-Boundary Impedance in High-Purity Stabilized Zirconia. J. Am. Ceram. Soc. 79, 1169-1180 (2005).

28. Liu, Y. L. \& Jiao, C. Microstructure degradation of an anode/electrolyte interface in SOFC studied by transmission electron microscopy TT -. Solid State lonics TA - 176, 435-442 (2005). 
29. Liu, Y. L., Primdahl, S. \& Mogensen, M. Effects of impurities on microstructure in Ni/YSZYSZ half-cells for SOFC TT -. Solid State Ionics TA - 161, 1-10 (2003).

30. Steele, B. C. H. \& Heinzel, A. Materials for fuel-cell technologies. Nature 414, 345 (2001).

31. Research, N. E. T. L.-I. \& National Energy Technology Laboratory (NETL) PA, and Morgantown, WV (United States), P. Oxygen reduction and transportation mechanisms in solid oxide fuel cell cathodes TT -. J. Power Sources TA - 195, 3345-3358 (2010). 


\section{Chapter 2: Effects of Thin Film Yttrium-Stabilized Zirconia on lonic Conductivity}

\subsection{Introduction to Ionic Conductivity of Yttrium Stabilized Zirconia}

Conductivity in yttrium-stabilized zirconia (YSZ) has been observed dating back to the 1890 's. Research efforts since then have focus on studying and optimizing the concentration of $\mathrm{Y}_{2} \mathrm{O}_{3}$ addition into $\mathrm{ZrO}_{2}$ for use in solid oxide fuel cells. YSZ serves as a suitable material in SOFCs due to its stability in both reducing and oxidizing environments. Pure zirconia exhibits three polymorphs at varying temperatures. At room temperature, it possesses monoclinic structure. Upon increasing temperature to $1,170^{\circ} \mathrm{C}$, zirconia exhibits tetragonal polymorph. At temperatures above $2,370^{\circ} \mathrm{C}$, zirconia stabilizes at in a cubic fluorite structure as shown in Figure $2.1 .^{1}$

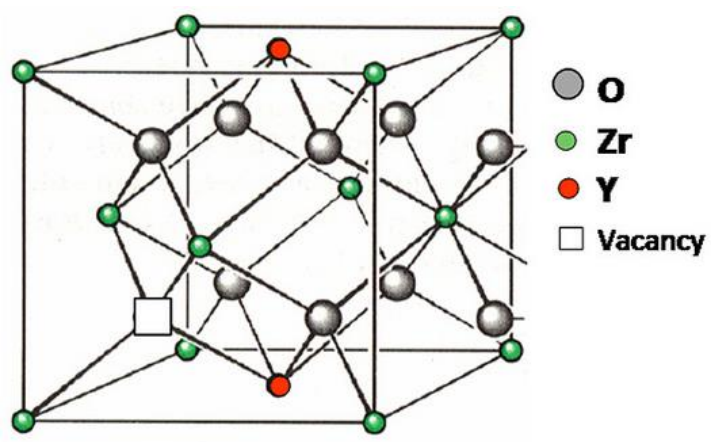

\section{Figure 2.4 YSZ cubic crystal structure structures ${ }^{2}$}

Oxygen ion conduction is a function of oxide ion vacancies and interstitial oxide ions. The cubic fluorite structure is face centered cubic arrangement. With cations and anions located in the tetrahedral sites, a large number of octahedral interstitial voids are present. This arrangement leads to open pathways for rapid ion diffusion. Zirconia exists in cubic structure at high temperatures or stabilized by the addition of an aliovalent cation. Intrinsic defects are related to thermodynamic equilibrium for pure zirconia. Extrinsic defects are produced by the introduction of aliovalent ions into the crystal lattice.

The addition of a cation into crystal with a different electrical charge compared to the host atoms produces a net charge in the crystal. To maintain electroneutrality, the addition of aliovalent ions is compensated by defects in the crystal. Pure ZrO2 has a small concentration of 
oxide ion vacancies and exhibits low ionic conductivity. When the addition of aliovalent ions such as yttrium ions are introduced, defects increase thus increasing conductivity.

In Kroger-Vink notation, the doping of yttria into pure $\mathrm{ZrO}_{2}$ is written in Equation 1. The dopant ion, yttrium, occupying a lattice site normally occupied by zirconia is indicated by $\mathrm{Y}_{\mathrm{zr}}$ in the expression below. This replacement of zirconia with yttrium causes an excess negative charge indicted by the superscript dash superscript. A vacancy in the lattice is indicated by the $\mathrm{V}$ with the subscript showing the normal lattice ion and superscript indicating the charge. Equation $3 \mathrm{Y}_{2} \mathrm{O}_{3}\left(\mathrm{ZrO}_{2}\right) \rightarrow 2 \mathrm{Y}_{\mathrm{Zr}}^{\prime}+3 \mathrm{O}_{O}^{x}+\mathrm{V}_{o}^{*}$

Ionic conductivity, $\sigma$, can be described as in Equation 2. Conductivity is a function of $n$ number of mobile oxide ion vacancies, $\mu$ mobility, and e electrical charge. The concentration of vacancies is dictated by the need of the lattice to maintain electrical neutrality. The vacancy concentration is linearly dependent on dopant level. Doping yttria into zirconia stabilizes the fluorite structure at room temperature. As dopant concentrations increase, vacancies that transport ions increase. A maximum conductivity is obtain at an appropriate dopant concentration. ${ }^{3}$ Equation $4 \sigma=e n \mu$

Oxide ions move through the crystal by hopping into unoccupied sites and should encounter minimum hindrance. Conductivity can also be described in Equation 3, where $E$ is the activation energy for oxide conduction, $\mathrm{R}$ gas constant, $\mathrm{T}$ absolute temperatures, and $\mathrm{A}$ exponential factor.

Equation $5 \sigma=A / T\left[V_{\ddot{O}}\right]\left(V_{\ddot{O}}{ }^{-1}\right) e^{-\frac{E}{R T}}$

Furthermore, ionic conductivity differs distinctly between polycrystalline materials and those with grains on the order of nanometers. Conflicting works have been reported on the effect of grain size on ionic conductivity. The manner in which samples were prepared may be the cause for discrepancies. Bulk specimens of ultrafine powers exhibited no change in activation energy while samples prepared as thin films exhibit a decrease in activation energy. Kosacki et al. ${ }^{4}$ observed significant improvements in total ionic conductivity in nanostructured $\mathrm{YSZ}$ and $\mathrm{CeO}_{2}-\mathrm{Gd}_{2} \mathrm{O}_{3}$ thin films when compared to microcrystalline or single crystal ceramics of the same composition. Nanocrystalline materials exhibit a unique interface with a high density 
of grain boundaries. The defect thermodynamics in the grain boundaries effect the energy required for ion hopping. The improvement of ionic conductivity in thin film YSZ was attributed to a decrease in activation energy due to the increase in ion mobility in the grain boundaries. Thin film conductivity was measured to be two orders of magnitude higher in nanocrystalline materials compared to polycrystalline. ${ }^{5}$ In the nanocrystalline material, resistance was largely determined by the grain boundary resistance. The author suggests the decrease in resistance was due to a decrease in impurity segregation. The increase in conductivity was also accompanied by a decrease in activation energy.

\subsection{Experimental Procedure}

Atomic layer deposition (ALD) is a deposition technique used to grow thin films based on the use of gas phases. ALD reactions occur with chemicals called precursors that react with a substrate though self-limiting surface reactions. ${ }^{6}$ Precursors are consecutively released or pulsed in to a reaction chamber to saturate the substrate surface. The pulses of different precursors are separated by a purging gas to inhibit reactions and contamination between precursors. Saturation of the substrate guarantees that the film growth is self-limiting. Therefore provided the pulse dose was high enough, the same amount of precursors are deposited across the substrate surface. Saturation of the substrate surface is verified by using an adequate pulse time length. Reasonable pulse times ensure reactants reach saturation. The self-limiting growth provides excellent deposition qualities. The film thickness is controlled by changing the number of deposition cycles without changing the quantity of each dose. Saturation of the substrate surface ensures uniform and conforming film thickness with low impurity levels.

Nanocrystalline yttrium stabilized zirconia thin films were fabricated onto YSZ substrates (Fuel Cell Materials) via a commercial atomic layer deposition (ALD) reactor for all depositions. The release of multiple cycles of precursors allows for the accumulation of the thin films to build to a desired thickness. The film thickness was measured via ellipsometry using a J.A. Woollam M-200U White Light Ellipsometer, and thickness was confirmed via TEM.

After fabrication of the YSZ thin films in the ALD reactor, the samples were subjected to surface conductivity measurements by utilizing the Van der Pauw technique. The power behind 
the Van der Pauw method is its ability to measure resistance on any arbitrary shape as long as it is approximately two dimension, therefore, applicable to measure the conductivity of thin films. $^{7}$

The Van der Pauw method utilized the four probe connection setup. With the use of a potentiostat (Solartron 1287A), four silver contacts were connected at the perimeter of the sample with gold paste. Current was measured between the working and counter electrodes; voltage measurements were taken between the working sense and reference electrodes. With current and voltage measured through separate electrodes, the resistance of the wires and connects was eliminated.

A simple cyclic voltammetry experiment was employed on the sample to measure resistance. Cyclic voltammetry varies current which causes a voltage drop across the sample. A voltammogram is plotted with current on the $x$-axis and voltage on the $y$-axis. Under the configuration in Figure 2.2 and with the use of Ohm's Law, resistance can be calculated with $R_{A B C D}=\frac{V_{C D}}{I_{A B}}$. The contacts are lettered $\mathrm{A}$ to $\mathrm{D}$ in a counter clockwise manner beginning in the top left. Reciprocal measurements, $R_{C D A B}$, are conducted by flipping the sides of the current and voltage measurements. By averaging $R_{A B C D}$ and $R_{C D A B}$, a more precise value can be obtained for the vertical resistance, $R_{\text {vertical }}=\frac{R_{A B C D}+R_{C D A B}}{2}$. Likewise two measurements are taken to obtain an average horizontal resistance $R_{\text {horizontal }}=\frac{R_{B C D A}+R_{D A B C}}{2}$.

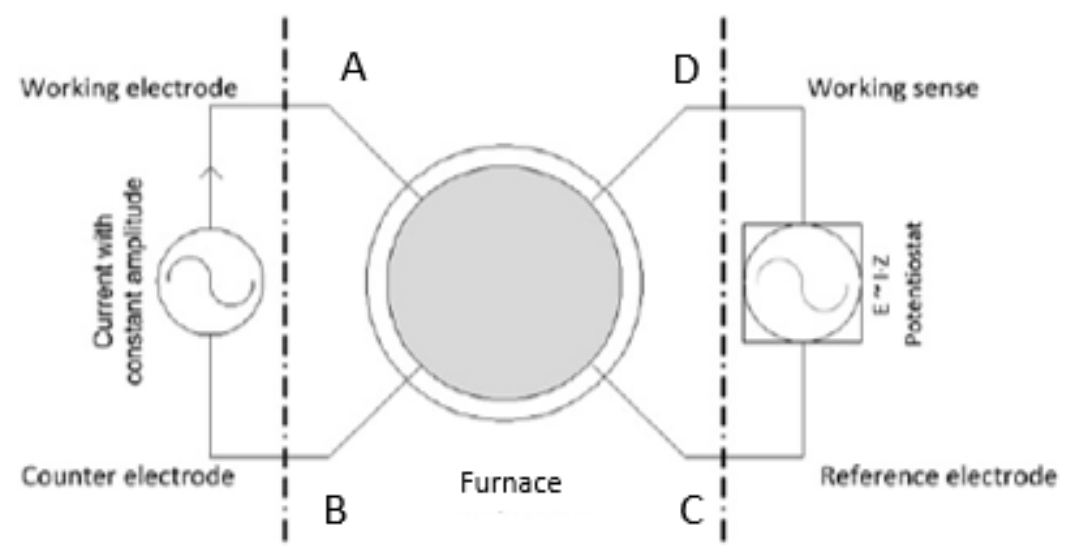

Figure 2.5. Schematic of the Van der Pauw setup measuring $R_{A B C D} \cdot{ }^{8}$ 
The use of Van der Pauw method requires the following conditions are satisfied: the sample must be flat with uniform thickness, cannot contain any isolated holes, must have a homogenous composition, electrode contacts must be at the edge of the sample, and the area of the electrode contacts must be much smaller in magnitude than the area of the entire sample. Upon these conditions being met, the Van der Pauw formula holds true where sheet resistance, $R_{s}$, with units of $\Omega / \square$ can be calculated from the experimentally measured resistances, $R_{\text {vertical }}$ and $R_{\text {horizontal }}$.

Equation 6. $e^{\left(\frac{-\pi R_{\text {vertical }}}{R_{S}}\right)+} e^{\left(\frac{-\pi R_{\text {horizontal }}}{R_{S}}\right)}=1$

$R_{s}$ was solved for in Equation 4 and resistivity is calculated by multiplying $R_{s}$ by the sample thickness. Activation energy is calculated by plotting the natural log of conductivity versus the inverse of temperature in Kelvin. Linear regression was applied to the data in order to find the equation of the line, $\ln (\sigma)=\left(\frac{-E_{A}}{R}\right)\left(\frac{1}{T}\right)+\ln \left(\sigma_{o}\right)$. Activation energy was determined by taking the slope of the line.

The conductivity of each sample was measured in air at $850^{\circ} \mathrm{C}, 750^{\circ} \mathrm{C}$, and $650^{\circ} \mathrm{C}$. Samples were subjected to a heat treatment of $850^{\circ} \mathrm{C}$ for 2 hours to crystalize the structure before conductivity measurements were collected. The samples were subjected to each temperature for 30 minutes to ensure an accurate temperature of the samples.

\subsection{Electrical Conductivity of Yttrium-Stabilized Zirconia Thin Films}

In the present work, a total of four samples having different surface treatments were investigated. By controlling the ALD processes, a uniform thin film was grown on the substrates. The samples measured by the ellipsometer had a uniform layer thickness of 28, 56, and $84 \mathrm{~nm}$. The thickness results from the ellipsometer matched those of the TEM.

The robustness and accuracy of the Van der Pauw method was first tested on a baseline YSZ pellet. Conductivity of the baseline YSZ pellet was in agreement with previously documented results. ${ }^{9,10}$ After verifying the Van der Pauw technique, the method was applied to the substrates with the additional nanostructured thin films. Figure 2.3 displays the conductivity of yttrium-stabilized zirconia thin films of varying thicknesses as a function of 
temperature. As expected for semiconductors, conductivity increased with temperature. Conductivity for all samples in this paper increased with an increase in temperature.

Furthermore, all simples with the additional surface thin film exhibited higher conductivity values compared to the baseline.

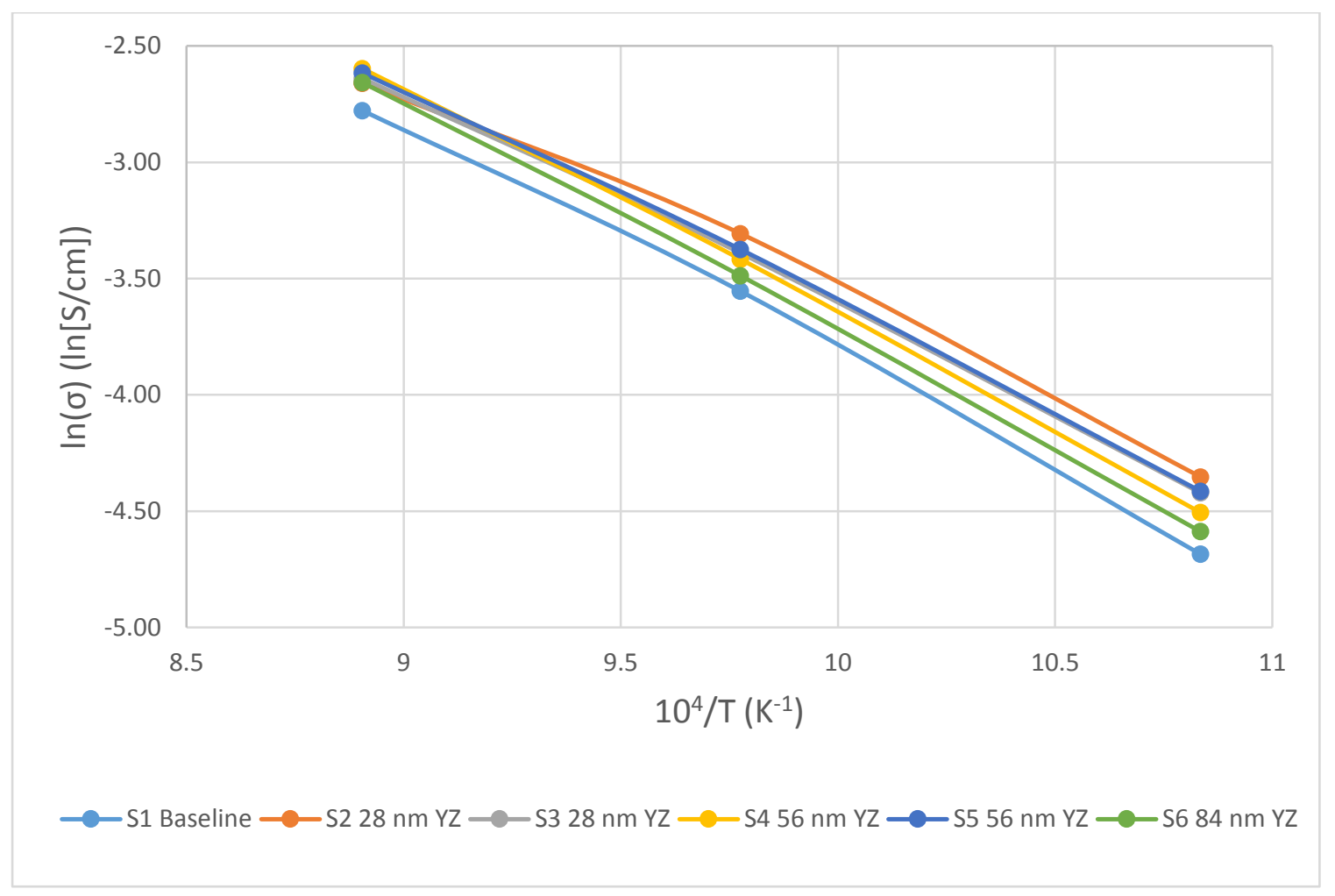

Figure 2.6. Electrical conductivity of thin films on YSZ substrate as a function of temperature.

Table 2.1 shows the conductivity values at the measured temperatures. Table 2.2 shows the percent increase in conductivity of each modified sample compared to the baseline sample. At $850^{\circ} \mathrm{C}$, conductivity of the samples with thin films tends to converge. At such temperature, the base substrate itself would have significant conductivity that could possibly mask any enhancement from the thin film. At lower temperatures such as $650^{\circ} \mathrm{C}$, the bulk conductivity of the substrate decreases and the effect from the thin films become more pronounced. At lower temperature, the conductivity values spread over a larger range which trends as a function of film thickness. At $650^{\circ} \mathrm{C}$, the increase in conductivity is correlated with film thickness. As the thin film thickness increases, conductivity of the samples decrease. Sample 2 which possess the thinnest film exhibited the highest conductivity. 
Table 2.1. Conductivity values for yttrium-zirconia thin films.

\begin{tabular}{ccccc}
\hline \multirow{2}{*}{ Sample } & \multirow{2}{*}{ Composition } & \multicolumn{3}{c}{ Conductivity, $\boldsymbol{\sigma}(\mathrm{S} / \mathrm{cm})$} \\
\cline { 3 - 5 } & & $\mathbf{8 5 0 ^ { \circ } \mathrm { C }}$ & $\mathbf{7 5 0}{ }^{\circ} \mathrm{C}$ & $\mathbf{6 5 0 ^ { \circ } \mathrm { C }}$ \\
\hline 1 & Baseline & 0.0622 & 0.0286 & 0.0092 \\
2 & $28 \mathrm{~nm} \mathrm{YZ}$ & 0.0699 & 0.0366 & 0.0129 \\
3 & $28 \mathrm{~nm} \mathrm{YZ}$ & 0.0714 & 0.0337 & 0.0120 \\
4 & $56 \mathrm{~nm} \mathrm{YZ}$ & 0.0745 & 0.0328 & 0.0110 \\
5 & $56 \mathrm{~nm} \mathrm{YZ}$ & 0.0731 & 0.0342 & 0.0121 \\
6 & $84 \mathrm{~nm} \mathrm{YZ}$ & 0.0701 & 0.0306 & 0.0102 \\
\hline
\end{tabular}

Table 2.2. Percent increase in conductivity of each sample with respect to the YSZ Baseline pellet.

\begin{tabular}{ccccc}
\hline \multirow{2}{*}{ Sample } & Composition & \multicolumn{2}{c}{$\begin{array}{c}\text { Percent Increase in Conductivity } \\
\text { Compared to Baseline (\%) }\end{array}$} \\
\cline { 3 - 5 } & & $\mathbf{8 5 0 ^ { \circ } \mathbf { C }}$ & $\mathbf{7 5 0 ^ { \circ } \mathbf { C }}$ & $\mathbf{6 5 0 ^ { \circ } \mathbf { C }}$ \\
\hline 2 & $28 \mathrm{~nm} \mathrm{YZ}$ & 12.4 & 28.1 & 39.4 \\
3 & $28 \mathrm{~nm} \mathrm{YZ}$ & 14.9 & 17.8 & 30.2 \\
4 & $56 \mathrm{~nm} \mathrm{YZ}$ & 19.8 & 14.7 & 19.6 \\
5 & $56 \mathrm{~nm} \mathrm{YZ}$ & 17.5 & 19.7 & 31.1 \\
6 & $84 \mathrm{~nm} \mathrm{YZ}$ & 12.8 & 6.9 & 10.2 \\
\hline
\end{tabular}

Table 2.3 contains the activation energy for each sample. Furthermore, the activation energy of each sample systematically varies as a function of film thickness. As the thickness increases, the activation energy increases. All samples had activation energy below the Baseline sample except for the sample with a thickness of $84 \mathrm{~nm}$. Sample 6 exhibited an activation energy higher than the Baseline sample. The grain size in the thin films would be largest in the Sample 6. As the grain size increases, the conductivity would be more dictated by 
the bulk grain and not the grain boundaries. The effect of the grain boundary conductivity could be diminished, leading to higher activation energy.

Table 2.3. Activation energies of samples.

\begin{tabular}{ccc}
\hline Sample & Composition & $\begin{array}{c}\text { Activation } \\
\text { Energy (eV) }\end{array}$ \\
\hline 1 & Baseline & 0.854 \\
2 & $28 \mathrm{~nm} \mathrm{YZ}$ & 0.758 \\
3 & $28 \mathrm{~nm} \mathrm{YZ}$ & 0.797 \\
4 & $56 \mathrm{~nm} \mathrm{YZ}$ & 0.853 \\
5 & $56 \mathrm{~nm} \mathrm{YZ}$ & 0.804 \\
6 & $84 \mathrm{~nm} \mathrm{YZ}$ & 0.862 \\
\hline
\end{tabular}

The conductivity measured in this experiment was the sum of both the substrate and thin film. The effect of the thin film on oxide conductivity was clearly shown. As discussed in the literature review and background, ionic conductivity in nanocrystalline materials differs distinctly from conventional grain sized materials. The resistance in polycrystalline materials of conventional grain size is dictated by the grain interiors. However, for nanocrystalline materials the grain boundary and grain bulk become comparable in size. Resistance in nanocrystalline materials is dictated by the properties of the grain boundary. The increase in conductivity in this work is likely attributed to the enhanced conduction in the grain boundaries. YSZ contain a large concentration of extrinsic defects. Impurities and defects tend to segregate to the grain boundaries to lower the strain of the bulk grain. An accumulation of change carriers to the grain boundary creates a space charge region. If the defects in the space charge region exhibit high mobility, conductivity is expected to increase. ${ }^{10}$ This material was fabricated as a thin film with a high density of grain boundaries, the defects with high mobility could explain the decrease in activation energy and thus increase in conductivity. 


\subsection{Summary of Results for Nanocrystalline Yttrium Stabilized Zirconia}

Yttrium stabilized Zirconia has been reported extensively in literature. The measured conductivity of the untreated YSZ pellet was well in agreement with previously reported values. Furthermore, the behavior of thin films and effect on conductivity are consistent with those reported in literature. The ionic conductivity results reported in this chapter support the reported difference in ionic conduction mechanisms between nanocrystalline structured materials and conventional polycrystalline solids, which was discussed in Chapter 1. ${ }^{5,11}$ All samples with the deposited film excited the conductivity of the baseline sample. Samples with thin films of YSZ exhibited a systematic increase in ionic conductivity and decrease in activation energy as film thickness decreased. 


\subsection{References}

1. Singhal, S. C. \& Kendall, K. T. A.-T. T.-. High-temperature solid oxide fuel cells : fundamentals, design, and applicatons. (2003).

2. NPTEL. Introduction to Fuel Cell technology - Overview. (2012). Available at: http://www.nptel.ac.in/courses/103102015/2.

3. Hui, S. (Rob) et al. A brief review of the ionic conductivity enhancement for selected oxide electrolytes TT -. J. power sources. TA - 172, 493 (2008).

4. Kosacki, I., Suzuki, T., Petrovsky, V. \& Anderson, H. U. Electrical conductivity of nanocrystalline ceria and zirconia thin films TT -. Solid state ionics. TA - 136, 1225 (2001).

5. Tuller, H. L. Ionic conduction in nanocrystalline materials. Solid State Ionics 131, 143-157 (2000).

6. Graziella, M. Chemical Vapour Deposition. Precursors, Processes and Applications. Edited by Anthony C. Jones and Michael L. Hitchman. Angew. Chemie Int. Ed. 48, 7478-7479 (2009).

7. Moroń, Z. Investigations of van der Pauw method applied for measuring electrical conductivity of electrolyte solutions: Measurement of electrolytic conductivity. Measurement 33, 281-290 (2003).

8. Allebrod, F., Chatzichristodoulou, C., Mollerup, P. L. \& Mogensen, M. B. Electrical conductivity measurements of aqueous and immobilized potassium hydroxide. Int. J. Hydrogen Energy 37, 16505-16514 (2012).

9. Joo, J. H. \& Choi, G. M. Electrical conductivity of YSZ film grown by pulsed laser deposition. Solid State Ionics 177, 1053-1057 (2006).

10. Zhang, Y. W. et al. Electrical conductivity enhancement in nanocrystalline (RE2O3)0.08(ZrO2)0.92 (RE=Sc, Y) thin films. Appl. Phys. Lett. 77, 3409-3411 (2000).

11. Guo, X. Can we achieve significantly higher ionic conductivity in nanostructured zirconia? TT -. Scr. Mater. TA - 65, 96-101 (2011). 


\section{Chapter 3: Effects of Thin Film Zirconia Oxide on Ionic Conductivity}

\subsection{Introduction to Nanocrystalline Conductivity}

Conductivity of polycrystalline ceramics are heavily influenced by the properties of the grain bulk and the grain boundaries. Optimizing the design of ceramic materials through manipulation of grain boundaries is essential to increase their performance. In solid oxide fuel cells, oxide conductors must exhibit high ionic conductivity, stability in reducing environments, and be thermally and mechanically compatible with the other components. ${ }^{1}$ Zirconia oxide is attractive for use in fuel cells due to fulfilling these requirements. Zirconia oxide, an insulating material with a relatively large band gap, exhibits satisfactory ionic conductivity at high temperatures or when stabilized by an aliovalent ion.

Nanocrystalline oxides exhibit unique properties that vary from conventional grain sized polycrystalline materials. Ionic conductivity in nanocrystalline materials is dictated by the grain boundary effects. ${ }^{2}$ Polycrystalline materials of the nanoscale exhibit high a high density of grain interfaces and defects. This clustering of defects increase the nonstoichiometry of the grains. Kroner $^{3}$ et. al measured the oxygen grain boundary diffusion coefficients of nanocrystalline YSZ. The grain boundaries demonstrated oxygen diffusivity that was 3 times the magnitude of the diffusivity in single crystals. The authors suggest that the concentration and mobility of oxygen vacancies are higher in the nanocrystalline sample than a doped single crystal.

\subsection{Experimental Procedure}

Zirconia oxide films were grown on YSZ substrates (Fuel cell Materials) by an atomic layer deposition reactor. The precursors were released in multiple cycles to tailor the film thickness to the desired level. Upon the fabrication of the thin films, the conductivity of the samples was measured in air in a furnace at $850^{\circ} \mathrm{C}, 750^{\circ} \mathrm{C}$, and $650^{\circ} \mathrm{C}$. The samples were subjected to a furnace at $850^{\circ} \mathrm{C}$ for 2 hours to crystalize the structure before conductivity measurements were collected. The conductivity measurements were taken 30 minutes after the furnace reached each respective temperature to ensure an accurate temperature of the sample. The Van der Pauw method as outline in Chapter 2 was used to measure conductivity 
with a potentiostat (Solartron 1287A). Silver leads were attached to the perimeter of the sample via gold paste. The film thickness was measured via ellipsometry using a J.A. Woollam M-200U White Light Ellipsometer and confirmed via TEM.

\subsection{Electrical Conductivity of Zirconia Thin Films}

In the present chapter, thin films composed of zirconia oxide were manufactured on YSZ substrates. The zirconia films thickness measured by ellipsometery was 27 nanometers; this thickness was in agreement from the results of the TEM. Figure 3.1 displays the conductivity of zirconia thin films as a function of temperature. The sample containing the thin film exhibited higher electrical conductivity compared to the baseline in the complete measured temperature range. Furthermore, two samples of the same composition were measured to observe the repeatability of the experiments. Both samples demonstrated nearly similar values for conductivity and activation energy.

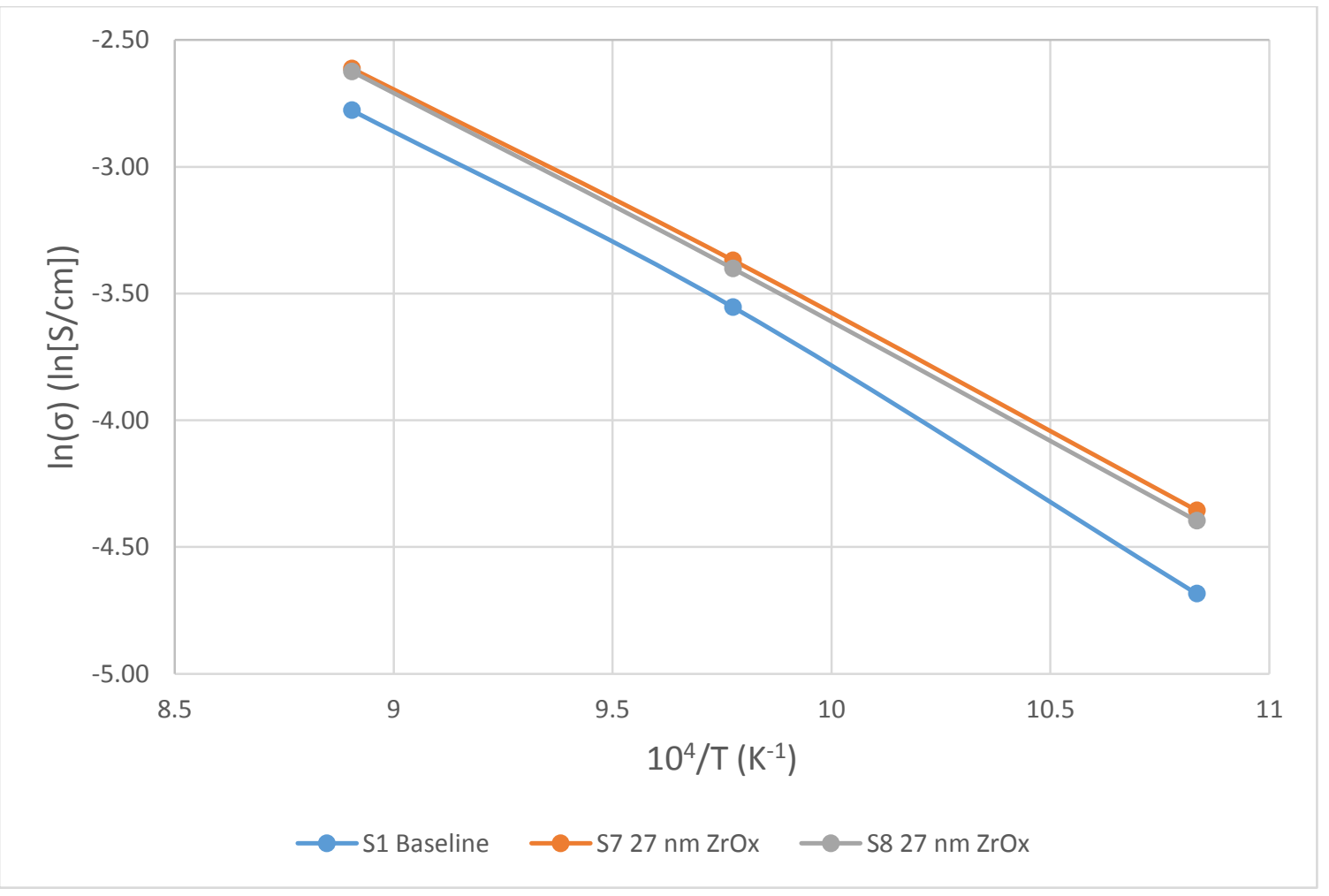

Figure 3.7. Electrical conductivity of zirconia oxide thin films as a function of temperature. 
Table 3.1 shows the conductivity values at the measured temperatures. Table 3.2 shows the percent increase in conductivity the samples with thin films compared to the baseline sample. When comparing the baseline and modified samples, the change in conductivity increases as the temperature decreases. This could be due to the substrate having reasonably high conductivity at $850{ }^{\circ} \mathrm{C}$. As the temperature decreases, the conductivity of the substrate decreased and the enhanced conductivity due to the additional thin film becomes more pronounced.

Table 3.4. Conductivity values for zirconia thin films.

\begin{tabular}{|c|c|c|c|c|}
\hline \multirow{2}{*}{ Sample } & \multirow{2}{*}{ Composition } & \multicolumn{3}{|c|}{ Conductivity, $\sigma(\mathrm{S} / \mathrm{cm})$} \\
\hline & & $850^{\circ} \mathrm{C}$ & $750^{\circ} \mathrm{C}$ & $650^{\circ} \mathrm{C}$ \\
\hline 1 & Baseline & 0.0622 & 0.0286 & 0.0092 \\
\hline 7 & $27 \mathrm{~nm} \mathrm{ZrOx}$ & 0.0733 & 0.0344 & 0.0128 \\
\hline 8 & $27 \mathrm{~nm} \mathrm{ZrOx}$ & 0.0725 & 0.0333 & 0.0123 \\
\hline
\end{tabular}

Table 3.5. Percent increase in conductivity of each sample with respect to the YSZ Baseline pellet.

\begin{tabular}{|c|c|c|c|c|}
\hline \multirow{3}{*}{ Sample } & \multirow{3}{*}{ Composition } & \multicolumn{3}{|c|}{ Percent Increase in Conductivity } \\
\hline & & \multicolumn{3}{|c|}{ Compared to Baseline } \\
\hline & & $850^{\circ} \mathrm{C}$ & $750^{\circ} \mathrm{C}$ & $650^{\circ} \mathrm{C}$ \\
\hline 7 & $27 \mathrm{~nm} \mathrm{ZrOx}$ & 17.9 & 20.3 & 39.0 \\
\hline 8 & $27 \mathrm{~nm} \mathrm{ZrOx}$ & 16.6 & 16.4 & 33.4 \\
\hline
\end{tabular}

Table 3.3 shows the calculated activation energy for the zirconia thin films. The samples with the zirconia thin film exhibited a substantial decrease in activation energy. This decrease in activation energy could be contributed to a high concentration and high mobility of oxygen vacancies in the nanocrystalline sample as suggested in previous works. 
Table 3.6. Activation energies of samples.

\begin{tabular}{ccc}
\hline Sample & Composition & $\begin{array}{c}\text { Activation } \\
\text { Energy (eV) }\end{array}$ \\
\hline 1 & Baseline & 0.854 \\
7 & $27 \mathrm{~nm}$ ZrOx & 0.779 \\
8 & $27 \mathrm{~nm}$ ZrOx & 0.792 \\
\hline
\end{tabular}

In this experiment, the Van der Pauw technique measured conductivity of both the substrate and thin film. The effect of the thin film on oxide conductivity was clearly shown. As discussed in the literature review and background, ionic conductivity in nanocrystalline materials differs distinctly from conventional grain sized materials. The increase in conductivity in this work is likely attributed to the enhanced conduction in the grain boundaries. Here zirconia oxide, an insulating material, increases conductivity of the substrate when deposited as a thin film. The polycrystalline film composed of nanosize grains contained a high density of interfaces. To lower strain within the grain bulk, defects could segregate to the grain boundary interfaces. An accumulation of defects to the boundary creates a space charge region. If the defects in the space charge region exhibit high mobility, conductivity is expected to increase. ${ }^{4}$ When this material was fabricated as a thin film with a high density of grain boundaries, the defects with high mobility could explain the decrease in activation energy and thus increase in conductivity.

\subsection{Summary of Results for Nanocrystalline Zirconia}

Zirconia has been reported extensively in literature. The behavior of thin films and effect on conductivity are consistent with those reported in literature. The ionic conductivity results reported in this chapter support the reported difference in ionic conduction mechanisms between nanocrystalline structure material and conventional polycrystalline solids that was discussed in Chapter $1 .^{5}$ Samples with thin films of zirconia exhibited an increase in ionic conductivity compared to the baseline sample and decrease in activation energy. 


\subsection{References}

1. Singhal, S. C. \& Kendall, K. T. A.-T. T.-. High-temperature solid oxide fuel cells : fundamentals, design, and applicatons. (2003).

2. Kosacki, I., Suzuki, T., Petrovsky, V. \& Anderson, H. U. Electrical conductivity of nanocrystalline ceria and zirconia thin films TT -. Solid state ionics. TA - 136, 1225 (2001).

3. Knöner, G., Reimann, K., Röwer, R., Södervall, U. \& Schaefer, H.-E. Enhanced oxygen diffusivity in interfaces of nanocrystalline ZrO\&lt;sub\&gt;2\&lt;/sub\&gt;· Y\&lt;sub\&gt;2\&lt;/sub\&gt;O\&lt;sub\&gt;3\&lt;/sub\&gt; Proc. Natl. Acad. Sci. 100, 3870 LP-3873 (2003).

4. Guo, X. Can we achieve significantly higher ionic conductivity in nanostructured zirconia? TT -. Scr. Mater. TA - 65, 96-101 (2011).

5. Tuller, H. L. Ionic conduction in nanocrystalline materials. Solid State Ionics 131, 143-157 (2000). 


\section{Chapter 4: Effects of Thin Film Manganese Doped Zirconia Oxide on Ionic Conductivity}

\subsection{Introduction}

The maximum power output of solid oxide fuel cells deviates from the expected total energy released from the electrochemical reactions. Imperfection in SOFC materials, structure, or design lead to polarization losses. ${ }^{1}$ Some of this lost energy is due to resistance from the electrical contacts and materials. However, a significant portion of polarization occurs due to insufficient reaction rates at the electrodes. An initial free energy is required to drive electrochemical processes at the electrode. Activation polarizing refers to this overpotential needed to act as a driving force. Cathodic reduction of oxygen leads to significant activation polarization and has consistently plagued engineers developing SOFC cathode materials. By improving cell design, these energy losses can be minimized.

Historically, SOFC cathodes are composed of LSM, but at low temperatures this material exhibits negligible ionic conductivity. The rate of molecular oxygen reduction and charge transport significantly decreases. ${ }^{2}$ This low conductivity limits oxygen surface exchange to the electrochemically active region where the charge transfer occurs, the triple phase boundary. Therefore, oxygen reduction only proceeds at the interface of the cathode, electrolyte, and gas phase. Thus this limited active region increases activation polarization losses. To combat the low ionic conductivity of the cathode, the material structure can be manipulated to increase vacancies for ionic conductivity and oxygen reduction reaction.

After fuel cells have been subjected to operation, manganese has reportedly diffused from neighboring LSM grains and to become enriched at the triple phase boundary region. ${ }^{3}$ Furthermore, manganese oxide is readily soluble in zirconia up to $14 \mathrm{wt} \%{ }^{4}$ The structure and conductivity of manganese doped zirconia has previously been with positive results. ${ }^{5,6}$ The doping of manganese oxide into $\mathrm{ZrO}_{2}$ is written in Eq. 1 in Kroger-Vink notation. The dopant ion, $\mathrm{Mn}^{3+}$, occupies a lattice site normally occupied by zirconia. The replacement of $\mathrm{Zr}^{4+}$ by $\mathrm{Mn}^{3+}$ induces excess negative charge into the crystal. To maintain charge neutrality, a vacant position is created in the crystal lattice. 
Equation $7 \mathrm{MnO}_{2} \rightarrow 2 \mathrm{Mn}_{\mathrm{Zr}}^{\prime}+3 \mathrm{O}_{O}^{x}+V_{o}^{*}$

The ionic conductivity of zirconia oxide was reported to systemically increase with increasing manganese concentration. Increasing the dopant concentration led to more oxygen vacancies in the crystal lattice. Oxygen vacancies are the charge carrier; therefore, higher concentration of vacancies results in higher ionic conductivity.

Furthermore, nanocrystalline oxides exhibit a unique structure with a high density of defects that leads to an increase ionic conductivity compared to polycrystalline materials of conventional grain sizes. The clustering of defects to the grain boundaries has reportedly increase grain boundary diffusion. Kroner et. $\mathrm{al}^{7}$ demonstrated an increase in oxygen diffusivity of 3 orders of magnitude of nanocrystalline YSZ compared to single crystal YSZ.

\subsection{Experimental Procedure}

Manganese and zirconia oxide films were grown on YSZ substrates supplied from Fuel Cell Materials by atomic layer deposition (ALD). The precursors and ozone were released in multiple cycles which allowed for the tailoring the film thickness and composition. After manufacturing of the thin films, the samples were subjected to a heat treatment to crystallize the structure. The conductivity of the samples was subsequently measured in air in a box furnace at $850^{\circ} \mathrm{C}, 750^{\circ} \mathrm{C}$, and $650^{\circ} \mathrm{C}$. The Van der Pauw method was used to measure surface conductivity of the thin films with the use of a potentiostat (Solartron 1287A). Silver leads were connected to the perimeter of the samples with gold paste. The thickness of the film was measured via TEM.

\subsection{Electrical Conductivity of Manganese Doped Zirconia Thin Films}

By controlling the atomic layer deposition process, a uniform thin film of manganese and zirconia oxide was grown on the YSZ substrates. The film thickness analyzed by TEM measured 28 nanometers. Figure 4.1 displays the conductivity of the thin films as a function of temperature. Two samples of the same composition were measured to observe the repeatability of the experiments. Both samples exhibited higher conductivity when compared to the baseline sample. Furthermore, the conductivity of both samples were in the vicinity of each other. 


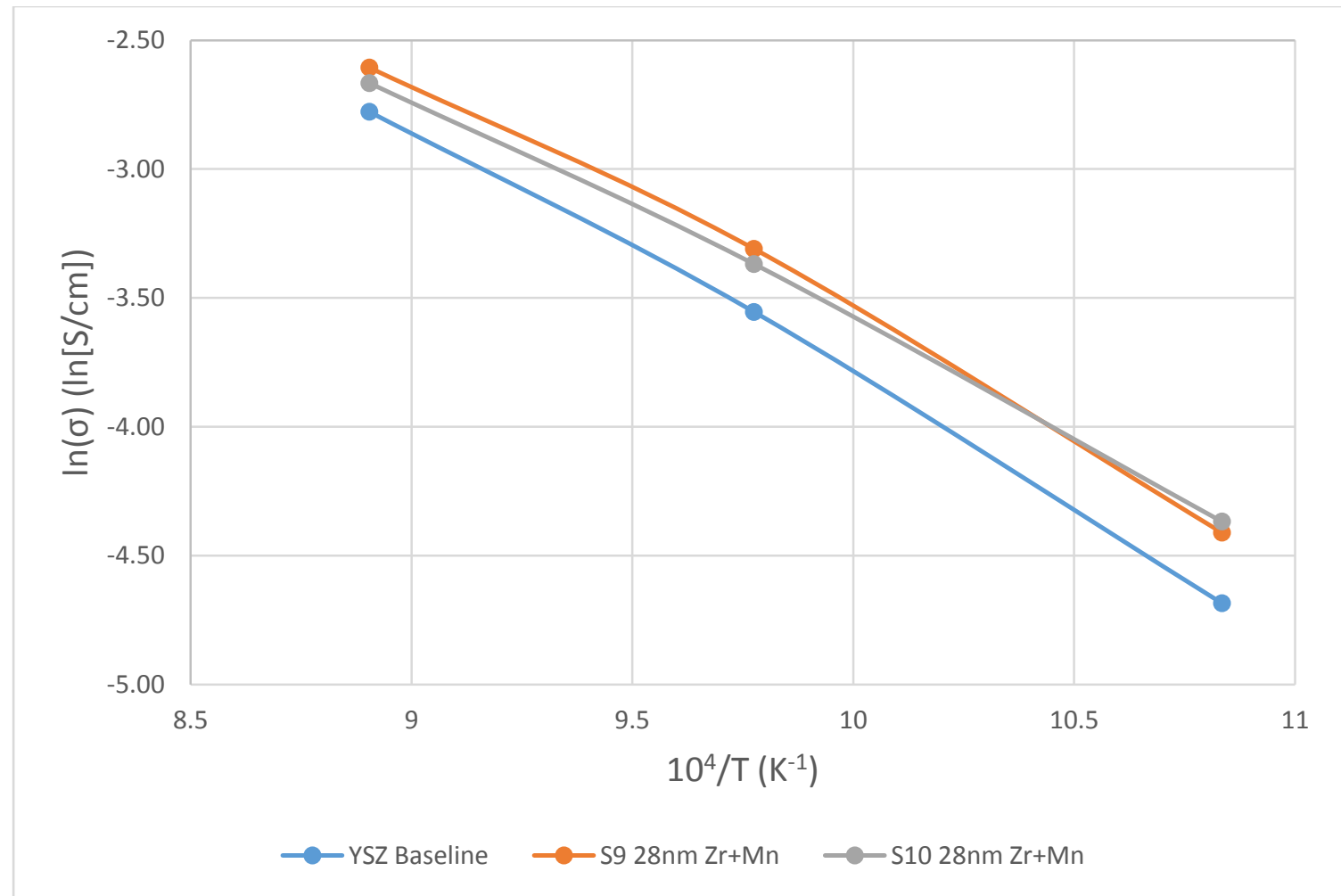

Figure 4.8. Electrical conductivity of thin films on YSZ substrate as a function of temperature.

Table 4.1 shows the conductivity values at the measured temperatures. Table 4.2 shows the percent increase in conductivity of each modified sample compared to the baseline sample. At $850^{\circ} \mathrm{C}$, the percent increase in conductivity is lowest at the three measured temperatures. At such temperature, the substrate would have significant conductivity that could possibly mask any enhancement from the thin film. At lower temperatures such as $650^{\circ} \mathrm{C}$, the bulk conductivity of the substrate decreases and the effect from the thin films become more pronounced. Both samples were subjected to the same treatment and experience nearly similar increases in conductivity. 
Table 4.7. Conductivity values for Manganese - Zirconia oxide thin films.

\begin{tabular}{|c|c|c|c|c|}
\hline \multirow{2}{*}{ Sample } & \multirow{2}{*}{ Composition } & \multicolumn{3}{|c|}{ Conductivity, $\sigma(\mathrm{S} / \mathrm{cm})$} \\
\hline & & $850^{\circ} \mathrm{C}$ & $750^{\circ} \mathrm{C}$ & $650^{\circ} \mathrm{C}$ \\
\hline 1 & Baseline & 0.0622 & 0.0286 & 0.0092 \\
\hline 9 & $28 \mathrm{~nm} \mathrm{Zr}+\mathrm{Mn}$ & 0.0738 & 0.0365 & 0.0121 \\
\hline 10 & $28 \mathrm{~nm} \mathrm{Zr}+\mathrm{Mn}$ & 0.0695 & 0.0345 & 0.0127 \\
\hline
\end{tabular}

Table 4.8. Percent increase in conductivity of each sample with respect to the YSZ Baseline pellet.

\begin{tabular}{ccccc}
\hline \multirow{2}{*}{ Sample } & Composition & \multicolumn{3}{c}{$\begin{array}{c}\text { Percent Increase in Conductivity } \\
\text { Compared to Baseline }\end{array}$} \\
\cline { 3 - 5 } & & $\mathbf{8 5 0}{ }^{\circ} \mathbf{C}$ & $\mathbf{7 5 0}{ }^{\circ} \mathbf{C}$ & $650^{\circ} \mathbf{C}$ \\
\hline 9 & $28 \mathrm{~nm} \mathrm{Zr+Mn}$ & 18.7 & 27.7 & 31.5 \\
10 & $28 \mathrm{~nm} \mathrm{Zr}+\mathrm{Mn}$ & 11.8 & 20.4 & 37.3 \\
\hline
\end{tabular}

Furthermore, the activation energy of each sample is shown in Table 4.3. Both samples with the zirconia and manganese thin films exhibited lower activation energy than the baseline samples. This decrease in activation energy could be contributed to a high concentration and high mobility of oxygen vacancies in the nanocrystalline sample as suggested in Chapter 1.

Table 4.9. Activation energies of manganese - zirconia samples.

\begin{tabular}{ccc}
\hline Sample & Composition & $\begin{array}{c}\text { Activation } \\
\text { Energy (eV) }\end{array}$ \\
\hline 1 & Baseline & 0.854 \\
9 & $28 \mathrm{~nm} \mathrm{Zr+Mn}$ & 0.809 \\
10 & $28 \mathrm{~nm} \mathrm{Zr+Mn}$ & 0.762 \\
\hline
\end{tabular}




\subsection{Summary of Results for Nanocrystalline Zirconia}

Zirconia and manganese oxide thin films were deposited onto YSZ substrates. Samples with thin films of zirconia and manganese oxide exhibited an increase in ionic conductivity compared to the baseline sample and decrease in activation energy. Ionic conductivity is dominated by the resistance of the grain boundaries at lower temperatures. The addition of manganese oxide to zirconia would create defects within the crystal lattice. These defects could then migrate to the grain boundaries. The ionic conductivity results reported in this chapter support the reported difference in ionic conduction mechanisms between nanocrystalline structure material and conventional polycrystalline solids. The behavior of thin films and effect on conductivity are consistent with those reported in literature as outline in Chapter 1. 


\subsection{References}

1. Singhal, S. C. \& Kendall, K. T. A.-T. T.-. High-temperature solid oxide fuel cells : fundamentals, design, and applicatons. (2003).

2. Brett, D. J. L., Atkinson, A., Brandon, N. P. \& Skinner, S. J. Intermediate temperature solid oxide fuel cells TT -. Chem. Soc. Rev. TA - 37, 1568-1578 (2008).

3. Backhaus-Ricoult, M. Interface chemistry in LSM-YSZ composite SOFC cathodes. Solid State lonics 177, 2195-2200 (2006).

4. P., D. V. et al. Stabilization of Cubic Zirconia with Manganese Oxide. J. Am. Ceram. Soc. 77, 2758-2762 (2005).

5. Beg, S., Sarita \& Varshney, P. Effect of $\mathrm{MnO} 2$ on the electrical conductivity of $\mathrm{ZrO} 2$ . Inorg. Mater. 42, 1083-1087 (2006).

6. Nandy, A., Tiwary, C. S., Dutta, A., Chattopadhyay, K. \& Pradhan, S. K. Effect of Manganese (II) Oxide on microstructure and ionic transport properties of nanostructured cubic zirconia TT -. Electrochim. Acta TA - 170, 360-368 (2015).

7. Knöner, G., Reimann, K., Röwer, R., Södervall, U. \& Schaefer, H.-E. Enhanced oxygen diffusivity in interfaces of nanocrystalline ZrO\&lt;sub\&gt;2\&lt;/sub\&gt; Y \&lt;sub\&gt;2\&lt;/sub\&gt;O\&lt;sub\&gt;3\&lt;/sub\&gt; Proc. Natl. Acad. Sci. 100, 3870 LP-3873 (2003). 


\section{Chapter 5: Background of Electrochemical Impedance Spectroscopy and Distribution of Relaxation Times}

\subsection{Introduction to Electrochemical Impedance Spectroscopy}

The performance of solid oxide fuel cells are strongly influenced by the composition and microstructure of the electrodes and electrolyte. Electrodes must diffuse reactants and products, exchange surface reactants, and transport ionic and electronic charges. Grain size, porosity, surface properties, and the interface between grains in the electrodes effect the impedance of fuel cells. ${ }^{1}$ Impedance data is commonly analyzed with equivalent circuit models and nonlinear least squares curve fitting, but due to the multitude of processes affecting the system, interpretation of impedance spectrum proves to be complicated.

Electrochemical impedance spectroscopy (EIS) is a commonly used technique to study the response of electrochemical systems. Electrical impedance is a measure of resistance applied to an AC circuit. Impedance contains both a magnitude and phase. When performing measurements, $A C$ voltage is supplied by a potentiostat and the resulting $A C$ current is measured. Voltage is of the form $E_{a c}=\left|E_{a c}\right| \sin (\omega t)$, where $\left|E_{a c}\right|$ is the magnitude of the $A C$ voltage, $\omega$ is the radial frequency, and $t$ is the time. Due to the capacitance in solid oxide fuel cells, the current and voltage from an AC impedance test do not peak at the same time. ${ }^{2}$ The AC current response is $\mathrm{I}_{\mathrm{ac}}=\left|\mathrm{I}_{\mathrm{ac}}\right| \sin (\omega \mathrm{t}+\varphi)$, where $\left|\mathrm{I}_{\mathrm{ac}}\right|$ is the magnitude of the $A C$ current, $\omega$ is the radial frequency, and $\phi$ is the phase shift. Current can be expressed as a complex number, $\mathrm{I}_{\mathrm{ac}}=\mathrm{I}^{\prime}+\mathrm{jI}^{\prime \prime}$, where $\mathrm{I}^{\prime}$ is the real or in-phase component, $\mathrm{I}^{\prime \prime}$ is the imaginary or out-of-phase component, and $\mathrm{j}$ is the square root of negative one. By definition, voltage has a phase of zero. Like resistance in DC current, $A C$ impedance is equal to voltage divided by current: $\mathrm{Z}=\frac{\left|\mathrm{E}_{\mathrm{ac}}\right|}{\mathrm{I}^{\prime}+\mathrm{jI}^{\prime \prime}}$. This equation can be reduced to impedance expressed as $Z=Z^{\prime}+j Z^{\prime \prime}$.

AC impedance is a powerful method used to measure and evaluate performance degradations in solid oxide fuel cells. The real and imaginary components of the impedance spectrum give insight to kinetic properties, mass transport properties, and surface properties 
from the double layer capacitance. Impedance data is represented graphically in Bode and Nyquist plots. The shapes of these graphs provide understanding into the performance of solid oxide fuel cells. In Figure 5.1, impedance data is plotted in a Nyquist plot where the $-Z^{\prime \prime}$ is plotted versus Z'; each point represents a measurement at one frequency.

The impedance spectrum intercepts or approaches the x-axis in two locations. The high frequency intercept on the Nyquist plot is the called series resistance, $R_{s}$. The series resistance is a measure of the Ohmic resistance. At the low frequency, the intercept represents the total resistance, $R_{t}$. Polarizations are voltage loses that arise due to imperfections in components structure and composition. Polarization resistance, $R_{p}$, is a measure of resistance from all the electrochemical processes within a fuel cell. In the Nyquist plot, polarization resistance is quantified by the difference between the high and low intercepts. At a given frequency, the impedance measurements contain contributions from relaxation times above and below the tested frequency; therefore, the impedance spectrum contains overlapping individual polarization processes. Advances in impedance modeling allow for increased clarification and the ability to identify individual physical processes in the impedance spectrum. 


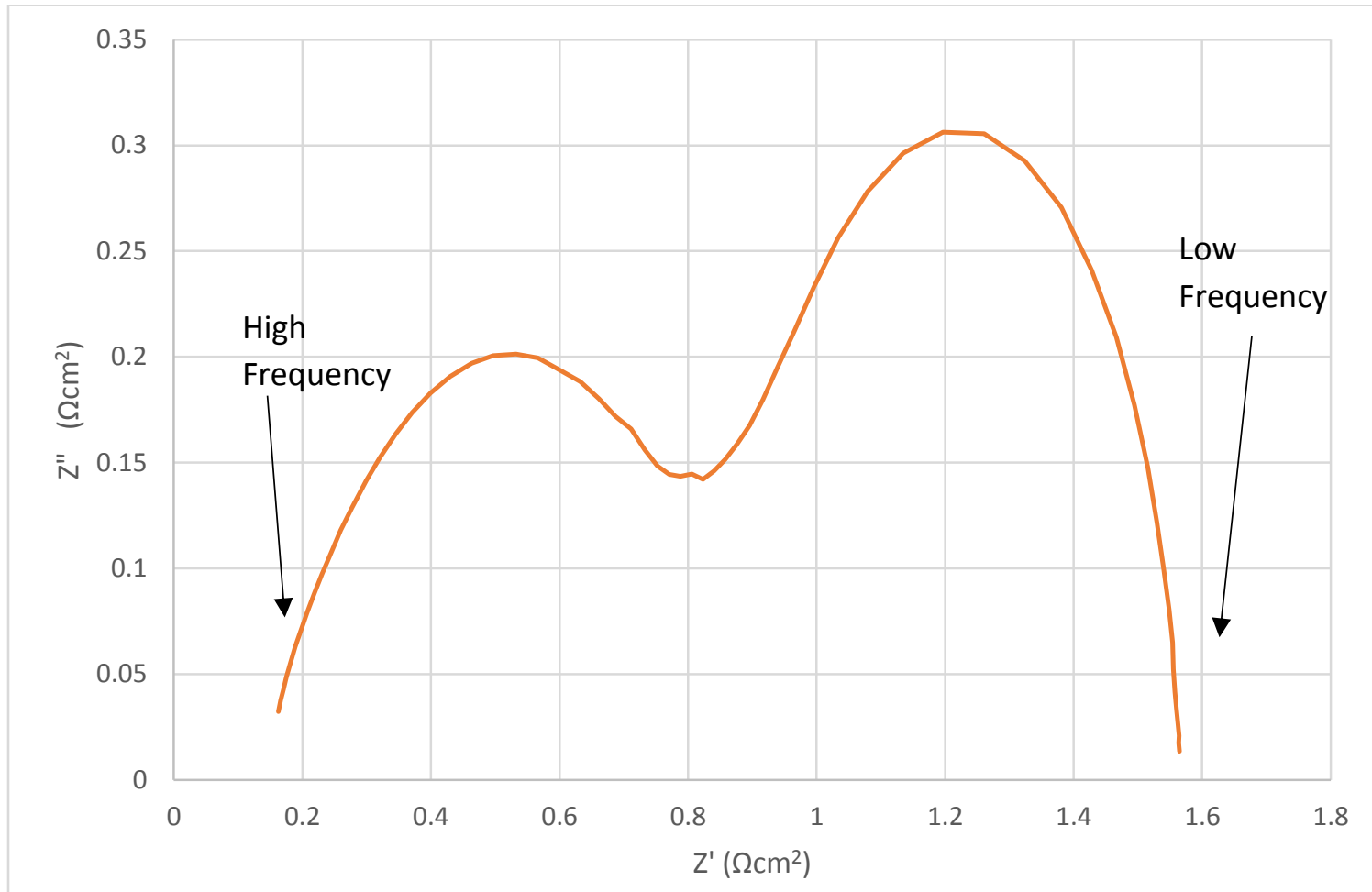

Figure 5.9. Nyquist Plot of a fuel cell with LSM cathode (Fuel Cell Material) at $750^{\circ} \mathrm{C}$.

\subsection{Background and Methodology to Distribution of Relaxation Times}

Electrochemical impedance spectroscopy and i-V response curves are typical methods used to characters electrochemical kinetics and reaction steps. Ideally, each charge transfer limiting process would surface as a discrete frequency arc on impedance diagrams. In contrast to Nyquist plots which contain overlapping processes, distribution of relaxation times resolves the impedance spectrum into a higher resolution plot were distinct polarization processes can be identified. ${ }^{3,4,5}$ The distribution of relaxation times of the complex impedance is represented as the following expression.

Equation $8 Z(\omega)=R_{O}+Z_{p}(\omega)=R_{O}+R_{p} \int_{0}^{\infty} \frac{\gamma(\tau)}{1+j \omega \tau} d \tau$

$R_{0}$ and $Z_{p}(\omega)$ represent the Ohmic and polarization parts of the complex impedance $Z(\omega)$, respectively. $R_{p}$ resents the total polarization resistance. The final term represents the fraction of the total polarization with relaxation times between $\tau$ and $\tau+d \tau$. The summation of the fractions is equal to the total polarization. 
The deconvolution of the impedance data was solved by Fourier transformation. ${ }^{6}$ The impedance data was collected by a potentiostat/galvanostat (Solartron 1287A) coupled with a frequency response analyzer (Solartron 1260). The data points were collected from $100 \mathrm{kHz}$ to $0.05 \mathrm{~Hz}$ in a logarithmic interval with ten steps per decade. It is assumed that the data is noise free or contains low noise. In the presented deconvolution method it is only necessary to consider the imaginary part of the impedance data. Imaginary impedance should be approaching zero at both the high and lower frequency limits. The presence of inductance can be noticed in a $-Z^{\prime \prime}$ versus $\log (f)$ plot where the impedance data is increasing at the high frequency limit. If necessary, the effect of inductance was removed from the high frequency end of the imaginary impedance. Inductive reactance is proportional to frequency and inductance. The data is corrected by adding $Z^{\prime \prime}$ and $\omega L$, where $\omega$ equal $2 \pi f$. A value of $L$ is chosen so that the $Z^{\prime \prime}$ data decays towards zero at in the high frequency end without going negative. 


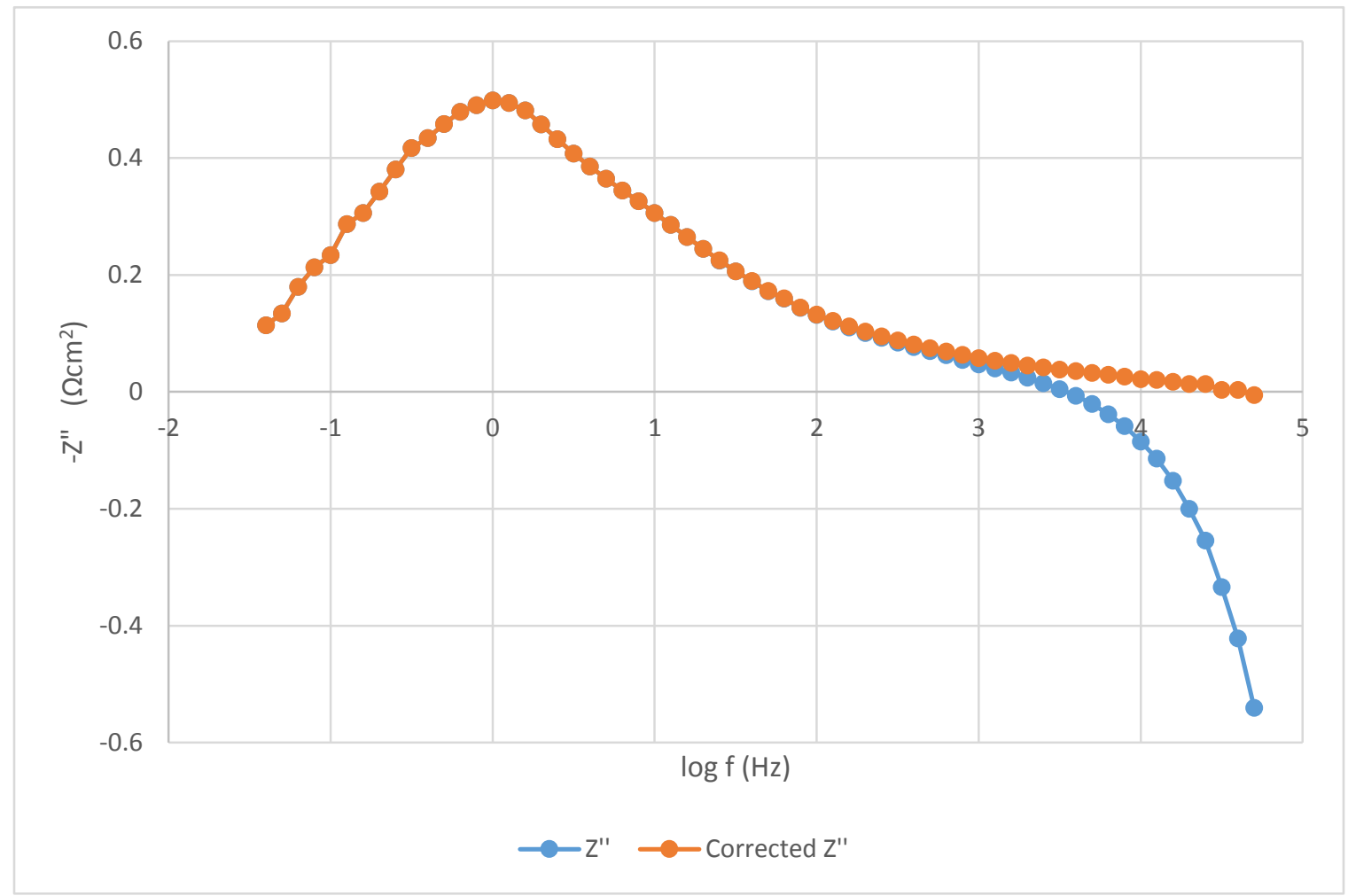

Figure 5.10. Example showing the removal of inductance from the $Z$ " data in the high frequency end.

When using the Fourier transformation method, the $Z^{\prime \prime}$ at the high and low frequency ends should be as close to zero as possible to minimize numerical errors. In reality, only a finite portion of the impedance spectrum can be captured. From the collected data, it is assumed at the highest and lowest frequencies only one physical process is active. Therefore, to reduce errors that arise from only collecting data over a finite range, linear regression was used to extrapolated the endpoints of $Z$ " to values close to zero. The extrapolated data was transposed by Fast Fourier Transport (FFT) in excel. The FFT function in excel requires $2^{\mathrm{N}}$ data points. The high frequency end was extrapolated from $\log (f)=5$ to $\log (f)=8$. The low frequency end was extended from $\log (f)=-1.2$ to $\log (f)=-4.7$. These extrapolations created 128 data points for the FFT. 


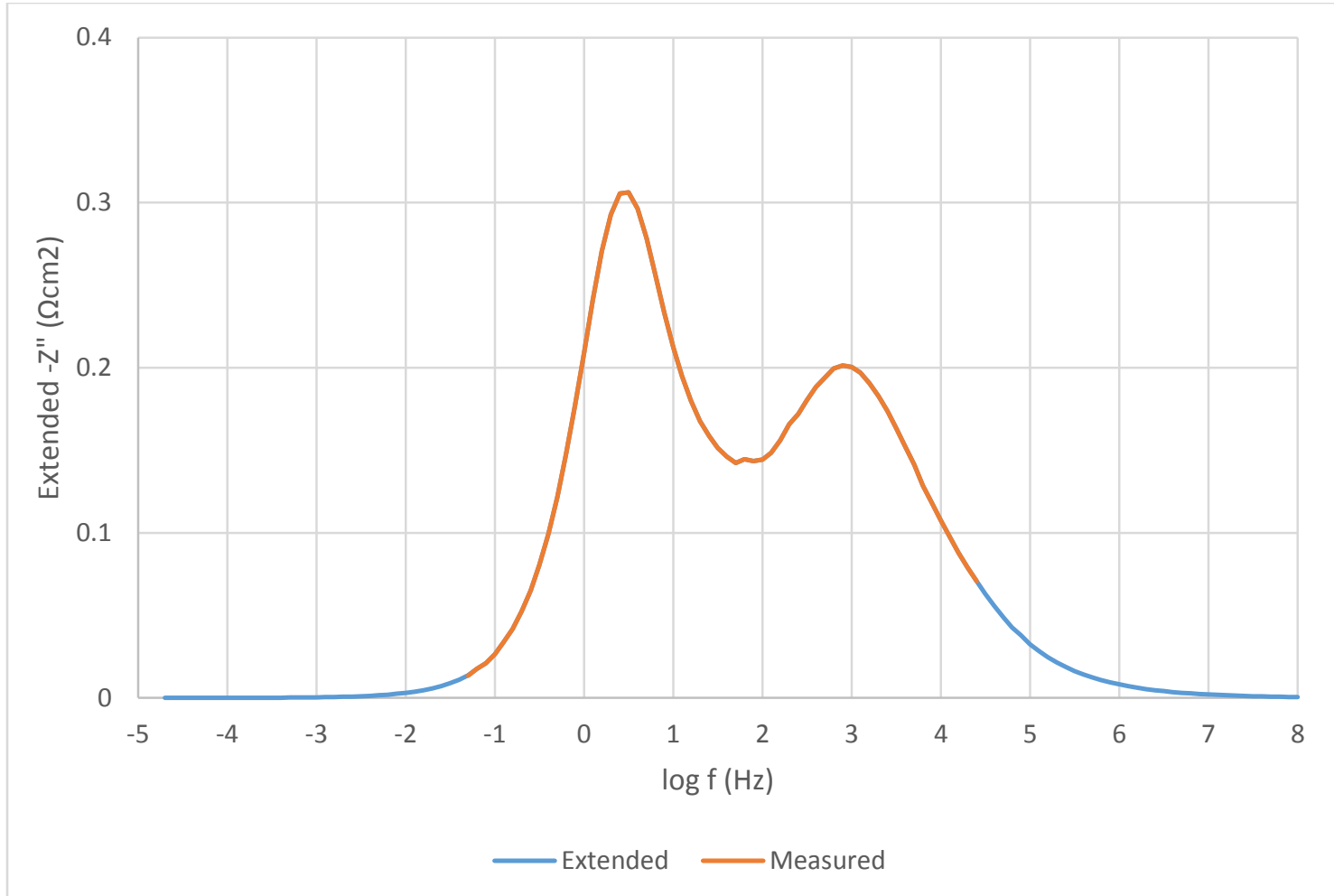

Figure 5.11. Comparison between the untreated data and the smoothed and extended data.

Because the Fourier method is only concerned with the imaginary impedance, $Z^{\prime \prime}$ can be considered as: $\mathrm{Z}^{\prime \prime}(\omega)=\int_{0}^{\infty} \frac{\omega \tau}{1+(\omega \tau)^{2}} \gamma(\tau) \mathrm{d} \tau$. This equation is rewritten in the deconvolution form as: $Z^{\prime \prime}(x)=-\frac{R_{\mathrm{p}}}{2} \operatorname{sech}(\mathrm{x}) * \mathrm{~g}(\mathrm{x})$ where $\mathrm{x}=\ln \left(\frac{\omega}{\omega_{0}}\right)$. The hyperbolic secant function was transposed using FFT. The transposed Z" elements were divided element wise by the corresponding component of the transposed hyperbolic secant function. The data set was then multiplied with a Hanning filter to remove noise; points outside the filter were eliminated. The Hanning filter is expressed as $\mathrm{w}=\left\{\frac{1}{2}-\frac{1}{2} \frac{\cos (\mathrm{n}-1)}{\mathrm{n}_{\text {filt }}} ;\left|\mathrm{n}-\mathrm{n}_{\text {filt }}\right|<\mathrm{n}_{\text {filt }} \quad 0 ;\left|\mathrm{n}-\mathrm{n}_{\text {filt }}\right|>\mathrm{n}_{\text {filt }}\right.$. The width of the filter was optimized to minimize excessive noise while still resulting in an appropriate resolution in the deconvolution spectrum. The width of the filter used was 23 . Therefore, the first and last 23 points are calculated with the equation above. An inverse Fast Fourier Transformation of the filter data resulted in the desired deconvolution of relaxation times. Each deconvolution spectrum was normalized and multiplied by its respective polarization resistance to allow for a comparison between different cell measurements. Figure 
5.4 shows the resulting deconvolution which is plotted as $g(f) * R p$ versus logged frequency. On the produced graph, each peak corresponds to a real physical process within the fuel cell, and the area under the curve represents the resistance arising from such process. The corresponding deconvolution in Figure 5.4 exhibits 4 peaks, meaning at least 4 electrochemical processes are present.

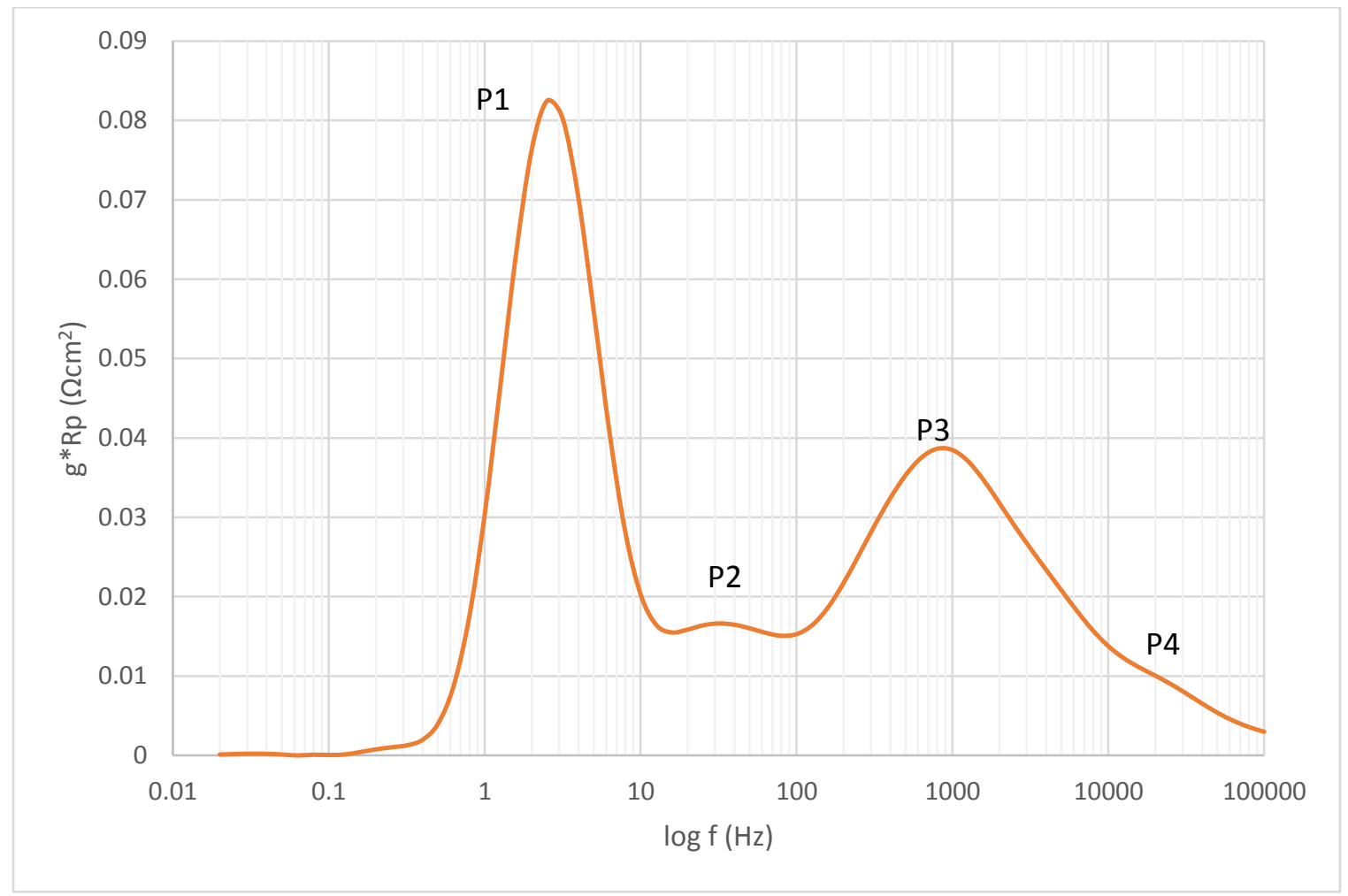

Figure 5.12. Distribution of Relaxation Times for LSM Cathode (Fuel Cell Materials)

In order to identify the peaks and ascribe each peak to a physical processes, multiple impedance measurements were conducted while systematically varying operating parameters. ${ }^{7,8,9,10}$ By purposefully subjecting the cell to conditions that has a negative effect on performance, the resistance from specific processes will increase. Upon performing the deconvolution, the change in resistance is shown by a corresponding change in a peaks height.

Changing certain operating parameters will inadvertently affect electrochemical processes within the fuel cell. Decreasing the hydrogen partial pressure in the anode fuel stream hinders the hydrogen gas diffusion. Also, water partial pressure in the anode will affect 
the charge transfer reaction at the anodic TPB. Decreasing the oxygen partial pressure in the cathode gas stream will hinders the oxygen gas diffusion and oxygen reduction reaction. Decreasing the operating temperature will decrease conductivity of the YSZ and hinder the oxygen reduction reaction. In the DRTs peaks correspond to a physical process and each peak occurs at characteristic frequency. Table 5.1 below is a survey of results previously reported in literature. Here each process is ascribed to the cathode or anode. Like physical processes have been grouped together. The frequency at which a peak occurs is noted. Previously reported results are in some agreement. Peaks corresponding to hydrogen gas diffusion in the anode occur in a range from 0.3 to $200 \mathrm{~Hz}$. Peaks corresponding to oxygen diffusion in the cathode occur in the rage of 0.25 to $158 \mathrm{~Hz}$. Elements in the DRT plot attributed to oxygen reduction reaction are reported to arise in the range from $10 \mathrm{~Hz}$ to $1,000 \mathrm{~Hz}$. Hydrogen charge transfer is reported to cause peaks in the range of $2,000 \mathrm{~Hz}$ to $20,000 \mathrm{~Hz}$. Oxygen ion transport through YSZ was reported to cause elements to arise in the DRT plot at frequencies around and above $10,000 \mathrm{~Hz}$. The locations of the peaks depend on the composition of the cell; therefore, deviations between researchers are reported. 
Table 5.10. Summary of DRT peak frequencies.

\begin{tabular}{|c|c|c|c|c|}
\hline Anode & Cathode & Physical Origin & $\begin{array}{l}\text { Peak Frequency } \\
(\mathrm{Hz})\end{array}$ & Reference \\
\hline \multirow{7}{*}{$x$} & & \multirow{7}{*}{ Hydrogen gas diffusion } & 8 & 4 \\
\hline & & & 5 & 11 \\
\hline & & & 5 & 8 \\
\hline & & & 0.3 & 7 \\
\hline & & & 10 & 9 \\
\hline & & & 200 & 9 \\
\hline & & & 60 & 10 \\
\hline & \multirow{4}{*}{$x$} & \multirow{4}{*}{ Oxygen gas diffusion } & 0.25 & 4 \\
\hline & & & 56 & 11 \\
\hline & & & 158 & 11 \\
\hline & & & 3 & 7 \\
\hline & \multirow{2}{*}{$x$} & \multirow{2}{*}{$\begin{array}{l}\text { Oxygen surface exchange kinetics and O2- } \\
\text { diffusivity in the bulk of the cathode }\end{array}$} & 10 & 4 \\
\hline & & & 100 & 4 \\
\hline & \multirow{4}{*}{$x$} & \multirow{4}{*}{$\begin{array}{c}\text { Adsorption of } \mathrm{O} 2 \text {, electrochemical reduction, } \\
\text { and transfer of oxygen species to TPB }\end{array}$} & 63 & 11 \\
\hline & & & 200 & 8 \\
\hline & & & 10 & 7 \\
\hline & & & 1,000 & 10 \\
\hline \multirow{5}{*}{$x$} & & \multirow{5}{*}{$\begin{array}{l}\text { Gas diffusion coupled with charge transfer } \\
\text { reaction and ionic transport }\end{array}$} & 2,000 & 4 \\
\hline & & & 30,000 & 4 \\
\hline & & & 2,000 & 8 \\
\hline & & & 20,000 & 8 \\
\hline & & & 4,000 & 11 \\
\hline \multirow{4}{*}{$\mathrm{x}$} & & \multirow{4}{*}{ Hydrogen charge transfer reaction } & 1,122 & 11 \\
\hline & & & 1,000 & 7 \\
\hline & & & $8,000-2,000$ & 9 \\
\hline & & & 4,000 & 10 \\
\hline \multirow{4}{*}{$\mathrm{X}$} & \multirow{2}{*}{$x$} & \multirow{2}{*}{ Oxygen ions transport in YSZ } & 8,912 & 11 \\
\hline & & & $30,000-20,000$ & 9 \\
\hline & \multirow{2}{*}{$\mathrm{X}$} & \multirow{2}{*}{$\begin{array}{l}\text { Oxygen ion transfer at LSM/YSZ interface and } \\
\text { YSZ }\end{array}$} & 10,000 & 7 \\
\hline & & & 50,000 & 10 \\
\hline
\end{tabular}




\subsection{Conclusion}

A method to perform the distribution of relaxation times was utilized. Through the distribution of relaxation times of electrochemical impedance spectroscopy, individual electrode processes in the anode and cathode can be characterized. The deconvolution of relaxation times enables the identification of individual processes from the impedance spectrum. Furthermore, this method allows for the quantification of such processes and enables one to see what processes contributes the largest proportion to the polarization resistance. This application can be applied to a range of issues involving the development of solid oxide fuel cells. The deconvolution of electrochemical impedance spectra can be applied to identify the effects operating conditions as well as the structure and composition of the electrodes. 


\subsection{References}

1. Boukamp, B. A. \& Rolle, A. Use of a distribution function of relaxation times (DFRT) in impedance analysis of SOFC electrodes TT -. Solid State Ionics TA - 314, 103-111 (2018).

2. Finklea, H. Electrical Impedance Spectroscopy. (2017).

3. Schichlein, H., Müller, A. C., Voigts, M., Krügel, A. \& Ivers-Tiffée, E. Deconvolution of electrochemical impedance spectra for the identification of electrode reaction mechanisms in solid oxide fuel cells TT -. J. Appl. Electrochem. TA - 32, 875-882 (2002).

4. Leonide, A., Rüger, B., Weber, A., Meulenberg, W. A. \& Ivers-Tiffée, E. Impedance Study of Alternative (La,Sr)FeO[sub 3- $\delta$ ] and $(\mathrm{La}, \mathrm{Sr})(\mathrm{Co}, \mathrm{Fe}) \mathrm{O}[\mathrm{sub} 3-\delta]$ MIEC Cathode Compositions TT -. J. Electrochem. Soc. TA - 157, B234 (2010).

5. A., L., V., S., A., W. \& E., I.-T. Evaluation and modeling of the cell resistance in anodesupported solid oxide fuel cells TT -. J. Electrochem. Soc. TA - 155, B36-B41 (2008).

6. Finklea, H., Chen, X., Gerdes, K., Pakalapati, S. \& Celik, I. Analysis of SOFCs Using Reference Electrodes TT -. JOURNAL- Electrochem. Soc. TA - 160, F1055 (2013).

7. Liu, B. et al. Analysis of Impedance Spectra for Segmented-in-Series Tubular Solid Oxide Fuel Cells TT -. J. Electrochem. Soc. TA - 157, B1858 (2010).

8. Kornely, M., Menzler, N. H., Weber, A. \& Ivers-Tiffée, E. Degradation of a High Performance SOFC Cathode by Cr-Poisoning at OCV-Conditions TT -. Fuel Cells TA - 13, 506-510 (2013).

9. Sonn, V., Leonide, A. \& Ivers-Tiffée, E. Combined Deconvolution and CNLS Fitting Approach Applied on the Impedance Response of Technical Ni/8YSZ Cermet Electrodes TT -. J. Electrochem. Soc. TA - 155, B675 (2008).

10. Barfod, R. et al. Detailed Characterization of Anode-Supported SOFCs by Impedance Spectroscopy TT -. J. Electrochem. Soc. TA - 154, B371 (2007).

11. Zhang, X. et al. Enhanced oxygen reduction activity and solid oxide fuel cell performance with a nanoparticles-loaded cathode. TT -. Nano Lett. TA - 15, 1703-1709 (2015). 


\section{Chapter 6: Distribution of Relaxation Times in Solid Oxide Fuel}

Cells

\subsection{Introduction}

SOFC prove to be a rising technology that provides sustainable and clean energy. Fuel cells are all ceramic devices that generate electricity by direct electrochemical conversion of a fuel. When the cell is subjected to operation polarizations, or voltage losses, occur across the cell due to imperfections in design and structure. Significant research is underway to improve the electrical performance and stability of these devices.

Diffusion of reactants, electrochemical reactions, and the transport of ions across phases in the anode and cathode contribute to the performance losses in SOFCs. In the cathode, oxygen modules must adsorb onto a solid surface and dissociate into oxygen atoms. Oxygen atoms migrate to a triple phase boundary where electron charge transfer reduces the oxygen to oxide ions. Oxide ions then become incorporated into the crystal lattice of YSZ and diffuse though the solid electrolyte to the anode. In the anode, hydrogen adsorbs onto the surface of YSZ or nickel and diffuses to the triple phase boundary. Hydrogen becomes oxidized by the oxide ions that were pumped though the electrolyte. This oxidation reaction releases electrons to an external circuit. ${ }^{1}$

The performance of solid oxide fuel cells are normally characterized through I-V response curves and electrochemical impedance spectroscopy. Electrochemical impedance spectroscopy is used to analyze the behavior of electrode processes; however, the typically analyzed plots, such as Nyquist and Bode plots, are unable to characterize individual processes. In contrast to the Nyquist plot where distinct processes overlap, distribution of relaxation times (DRT) resolves the impedance spectrum into a higher resolution plot where individual polarization processes can be identified..$^{2,3,4}$ Each electrochemical process can be discretely identified if the relaxation frequencies are separated by half a decade. ${ }^{5}$ The DRT creates a plot of $g(f) * R_{p}$ versus logged frequency. The plot consists of a series of peaks or shoulders in which ideally each element corresponds to one physical phenomena. The area under each peak reflects the resistance of a corresponding physical processes; therefore, the larger the area under the peak, the higher the resistance of that process. With the use of DRT, processes that 
contribute the largest proportion of resistance can be identified and then targeted for improvement.

\subsection{Methodology to Distribution of Relaxation Times}

In the present chapter, a commercially available anode supported solid oxide fuel cell (ASC-2.7, NexTech Materials, Ltd.) was operated in an in-house test station. The cell consisted of a $240 \mu \mathrm{m}$ thick Ni/YSZ (yttrium stabilized zirconia) layer anode, a dense $8 \mu \mathrm{m}$ thick YSZ electrolyte, and a LSM-GDC $50 \mu \mathrm{m}$ thick cathode. The diameter of the anode and electrolyte were $27 \mathrm{~mm}$ while the cathode area was $12.5 \mathrm{~mm}$. $\mathrm{H}_{2}$ was used at the fuel. Air was used to supply oxygen. The fuel and air streams were controlled via mass flow controllers. Cells were subjected to a constant current density of $0.3 \mathrm{~A} / \mathrm{cm}^{2}$. The cell impedance was collected with a potentiostat/galvanostat (Solartron 1289A) coupled with a frequency response analyzer (Solartron 1260). All impedance measurements were taken at open circuit conditions.

The impedance data was collected and the deconvolution of the impedance data was solved by Fourier transformation. ${ }^{6}$ The spectrum was recorded logarithmically with ten steps per decade from $100 \mathrm{kHz}$ to $0.05 \mathrm{~Hz}$. To reduce numerical errors in the Fourier transformation, the $Z^{\prime \prime}$ values should be close to zero at the high and low frequency limits. In practical measurements, only part of the spectrum is captured over a finite range; therefore, a linear regression was used to extend the endpoints of $Z^{\prime \prime}$ to values close to zero. This was performed under the assumption that only one physical process was active at the highest and lowest frequencies.

The extrapolated imaginary impedance was transposed by Fast Fourier Transformation (FFT) and subsequently divided by the corresponding element of the transformed hyperbolic secant function. The transposed data was then subjected to a Hanning filter for noise removal. An inverse Fast Fourier Transformation of the filtered data yielded the desired deconvolution of relaxation times. Each deconvolution distribution was normalized and multiplied by its respective polarization resistance. This allowed for a comparison between different impedance measurements. Polarization resistance was determined by fitting the impedance data in the computer software ZView2. In the resulting plot of $g(f)^{*} R_{p}$ vs log frequency, each peak corresponded to an individual physical phenomenon in the solid oxide fuel cell. To ascribe each 
peak to a physical process, the cell was subjected to tests where the operating parameters were systematically varied. By changing the operating conditions to purposefully affect one process in the fuel cell, the resulting DRT is altered to reflect such increase in resistance from the effected process.

\subsection{Results of the Distribution of Relaxation Times}

The DRT consists of a series of peaks or shoulders. Each element of the curve corresponds to a physical phenomenon that the cell experiences under operation. The area under each peak represents the resistance arising from the physical processes. Processes contributing the largest portion of resistance will have the highest peaks. In order to identify the peaks and ascribe each peak to a physical processes, multiple impedance measurements were conducted while systematically varying operating parameters..$^{5,7,8,9}$ The shape, area below the peak, and frequency at which the peak occurs depends on the operating parameters. Therefore, only one physical phenomenon should be effected and the cause for a peak change can be narrowed down.

The dependency of anodic processes were analyzed by changing the anode gas concentration. The fuel, hydrogen, concentration was altered from $100 \%$ to $60 \%$. All other parameters were kept constant. The impedance measurements were taken at open circuit conditions at $750^{\circ} \mathrm{C}$. Figure 6.1 shows the distribution of relaxation times recorded for various hydrogen partial pressures. Four distinct and separated peaks, labeled as PX, are visible in the DRT. The shape, area below the peak, and frequency at which the peak occurs depends on the operating parameters. $\mathrm{P} 1$, which crests at $3 \mathrm{~Hz}$, is clearly affected by the changes in the anode gas concentrations. P1 increases with decreasing hydrogen partial pressure while no other peaks are affected. Decreasing the hydrogen would hinder gas diffusion thus causing higher resistance. P1 represents the diffusion of hydrogen in the anode structure. The characteristic frequency of anodic gas diffusion determined in this paper are in agreeance from previously reported results. 8,10 


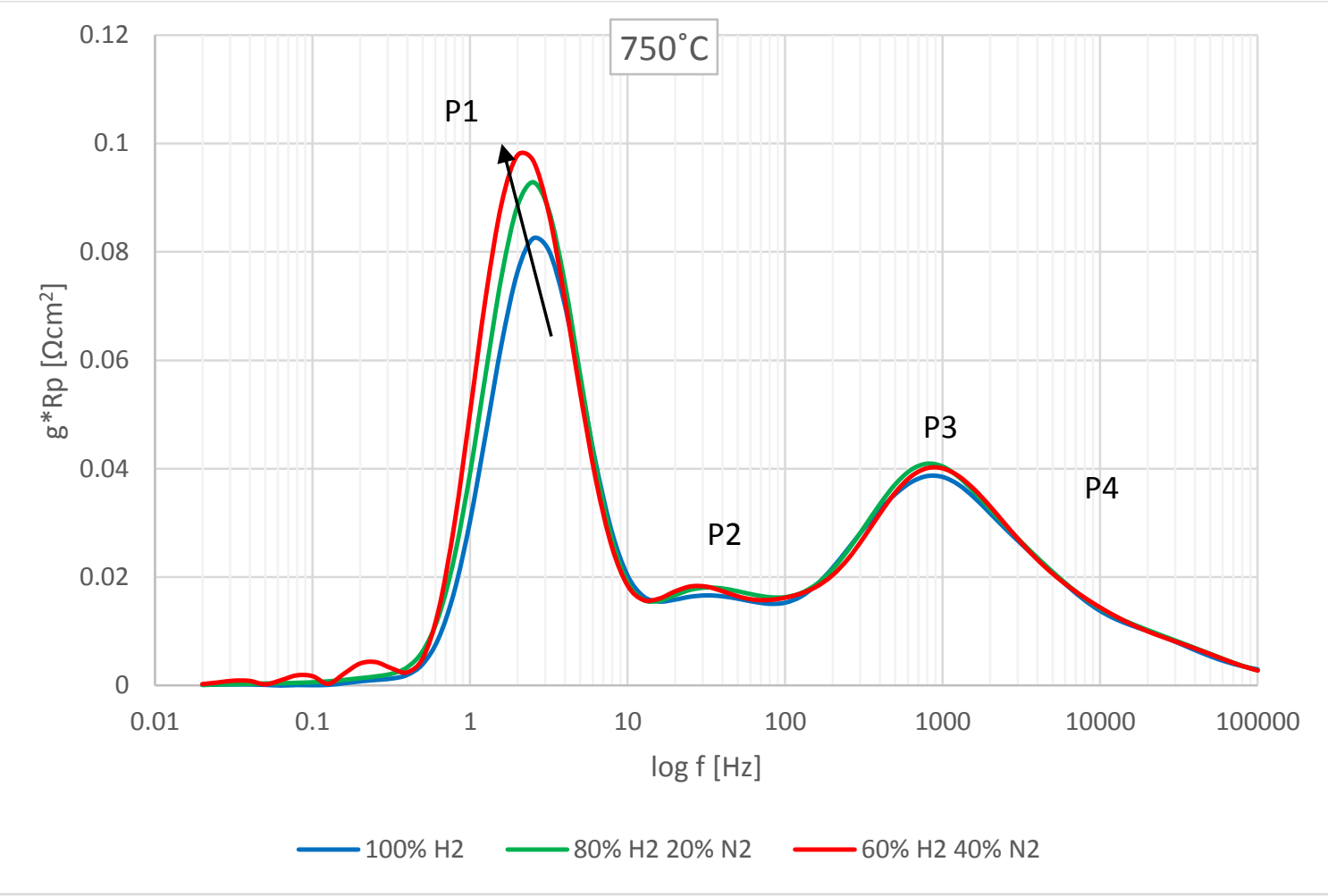

Figure 6.13. Series of DRT measured at three different hydrogen partial pressures in the anode.

The dependency of cathodic processes was analyzed by changing the cathode gas concentration. Oxygen partial pressure was altered from $20 \%$ to $5 \%$ and analyzed at two temperatures, $750^{\circ} \mathrm{C}$ and $700^{\circ} \mathrm{C}$. The cathode atmosphere was balanced with nitrogen. The hydrogen partial pressure in the anode was held constant at $100 \%$. The effect of decreasing oxygen partial pressure is clearly shown in Figure 6.2. In the corresponding DRT plot, P1 at $3 \mathrm{~Hz}$ significantly increases. Furthermore, P3 shifts to lower frequencies and increases in magnitude. In Figure 6.3, oxygen partial pressure was also altered from $20 \%$ to $5 \%$ but at an operating temperature of $700^{\circ} \mathrm{C}$. Similar to the DRT at $750^{\circ} \mathrm{C}, \mathrm{P} 1$ at $3 \mathrm{~Hz}$ increases in magnitude. The resistance increase in $\mathrm{P} 1$ is relatively the same at both temperatures; P1 could also be ascribed to oxygen gas diffusion in the cathode structure. Cathodic gas diffusion was also reported to occur at $3 \mathrm{~Hz}$ by Lui et al. ${ }^{5}$ Furthermore, $\mathrm{P} 3$ increases in magnitude and shifts to a lower frequency to overlap P2. Process 2 and process 3 are both thermally activated as well dependent on oxygen partial pressure. These peak in the frequency range of $10 \mathrm{~Hz}$ to $1000 \mathrm{~Hz}$ is likely due to electrochemical reaction in the cathode. ${ }^{11}$ Oxygen reduction reaction is a thermally activated process, thus leading to infer that both $\mathrm{P} 2$ and $\mathrm{P} 3$ are related with the adsorption and 
charge transfer of oxygen in the cathode. The deconvolution method can induce artificial peaks at the extremities of the deconvolution curve; the fluctuations at the highest and lowest frequencies in Figure 6.3 are likely artificial.

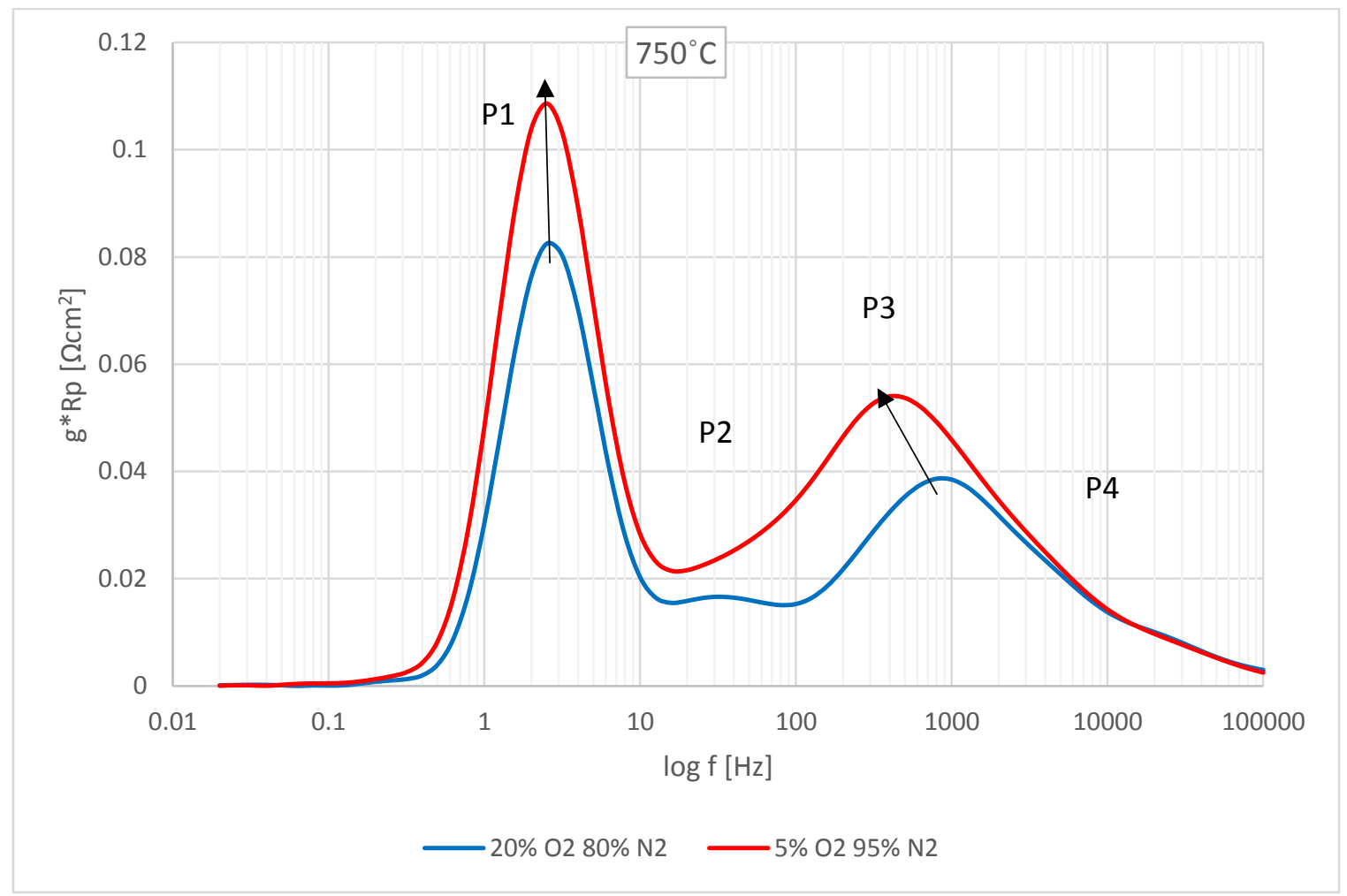

Figure 6.14. Comparison between DRT of varying oxygen partial pressure at $750^{\circ} \mathrm{C}$. 


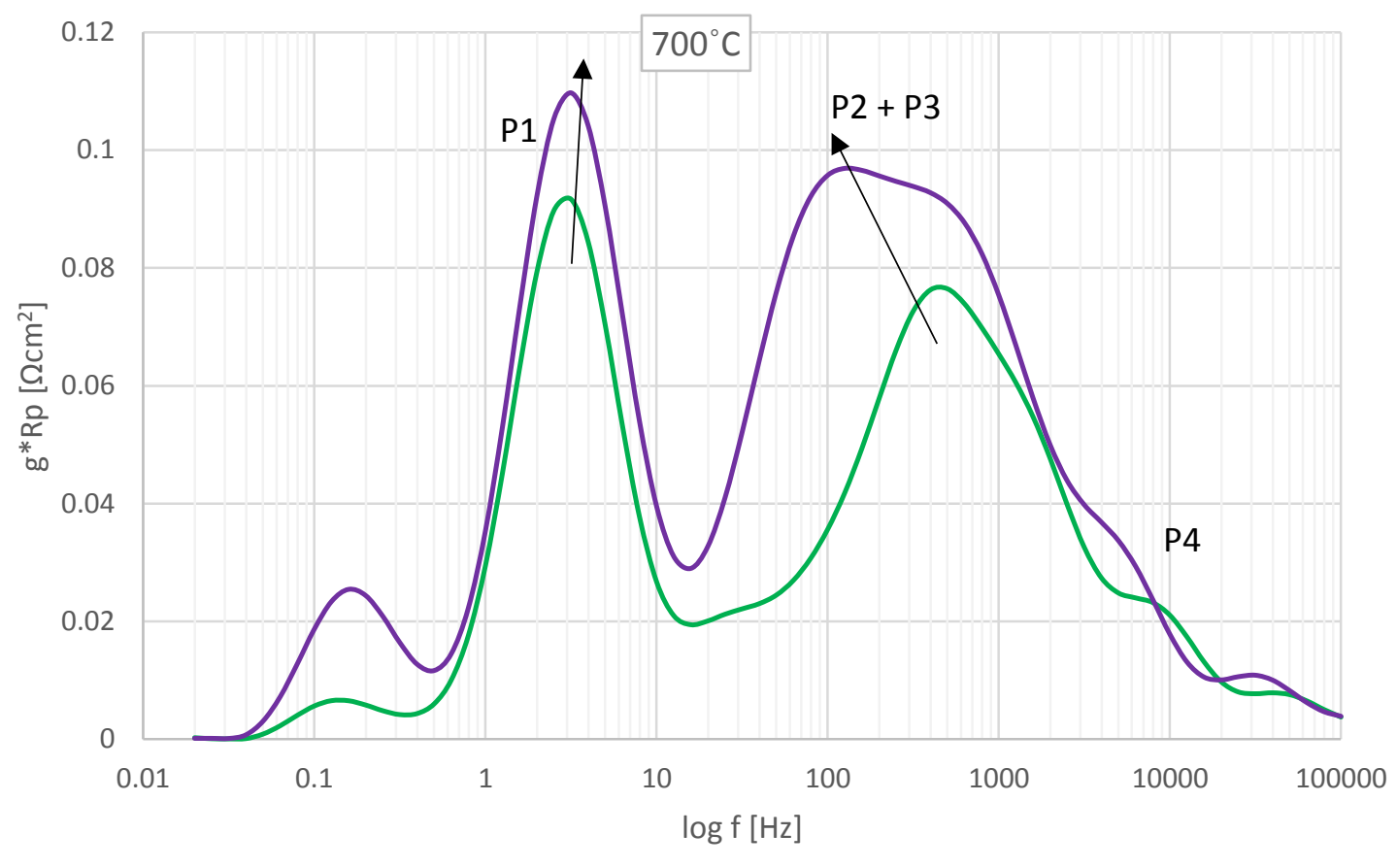

$-20 \%$ O2 80\% N2 - $5 \%$ O2 95\% N2

Figure 6.15. Comparison between DRT of varying oxygen partial pressure at $700^{\circ} \mathrm{C}$.

The effect of operating temperature was analyzed by DRT. Figure 6.4 displays the DRT for the baseline cell operating at $750^{\circ} \mathrm{C}, 700^{\circ} \mathrm{C}$, and $650^{\circ} \mathrm{C}$. Four peaks are shown on the DRT, and it is assumed that each peak corresponds to physical processes. Upon decreasing the operating temperature, each peak rises; therefor, the resistance from each process increases. P4 is only affected by the decrease in temperature and is not altered when changing the anode or cathode gas concentration. The dependency of P4 on temperature could lead to suspect that this processes can be ascribed to oxide ion transport though YSZ which is in line with reported results. ${ }^{10}$ Oxygen reduction is thought to be most difficult reaction to activate in SOFCs operating at lower temperatures. ${ }^{12}$ Upon decreasing the operating temperature, the resistance of the process behind P3 increases dramatically to overcome the resistance of P1. 


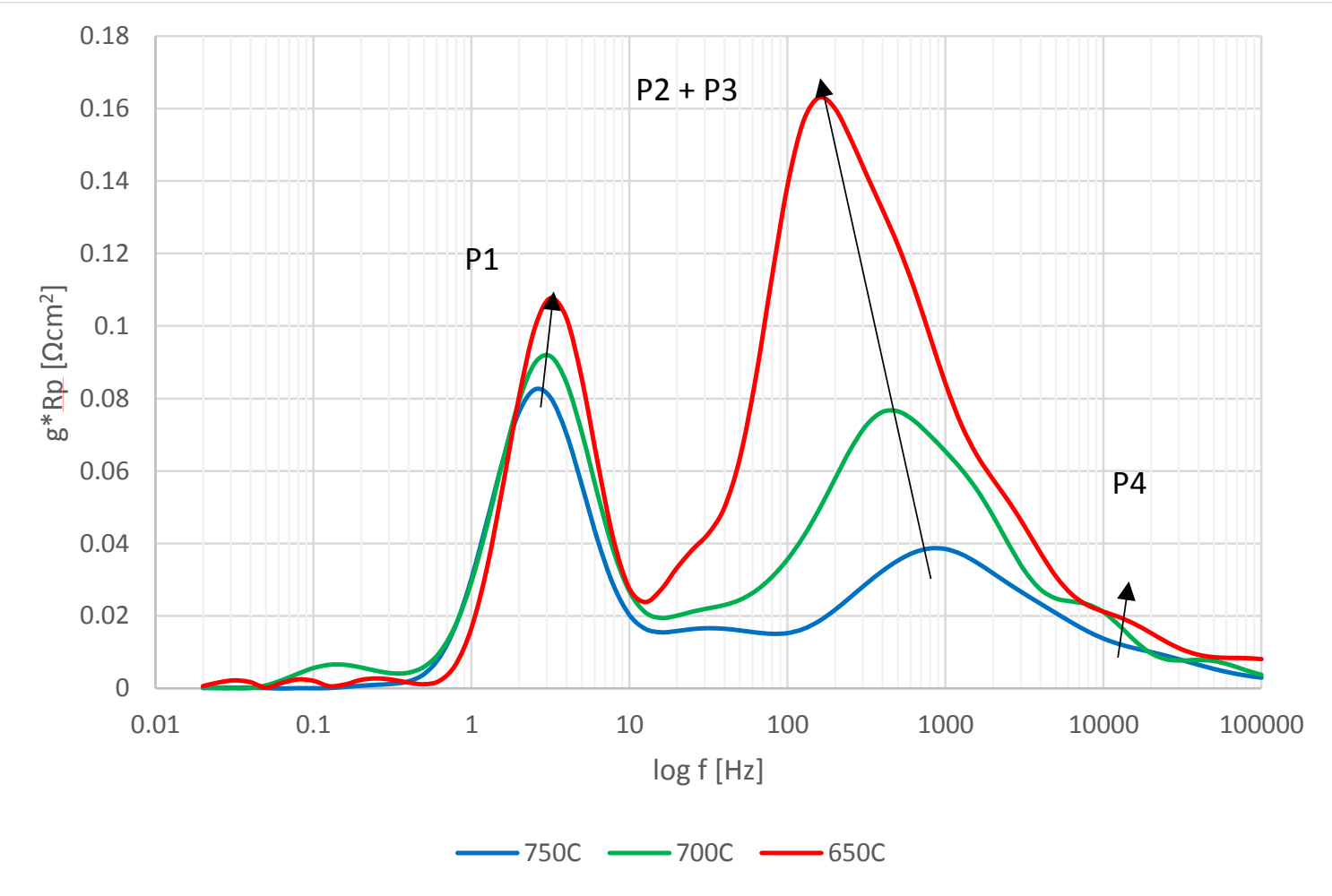

Figure 6.16. Series of DRT at three different operating temperatures.

\subsection{Summary of Results}

The deconvolution of distribution of relaxation times was implemented to give insight into the electrochemical process of the anode and cathode. The operating parameters were varied to determine the physical meaning behind each peak. Peak 1 at $3 \mathrm{~Hz}$ can be ascribed to gas diffusion in both the anode and cathode. P2 and P3 were functions of both temperature and oxygen partial pressure. P2 at $30 \mathrm{~Hz}$ and P3 at $800 \mathrm{~Hz}$ can be ascribed to oxygen reduction reaction. Peak 4 is only a function of temperature and could be ascribed to oxygen ions transport in the YSZ interfaces. The processes behind Peak 1 contribute the largest proportion to the total resistance of the cell at an operating temperature of $750^{\circ} \mathrm{C}$. However, upon decreasing the operating temperature, the resistance of Peak 2 and Peak 3 increase considerably. Peak 2 and Peak 3 correspond to charge transfer reactions in the cathode. As mentioned in the literature review, activation polarization greatly contributes to the performance loss in solid oxide fuel cells at lower operating temperatures due to slow reaction kinetics of oxygen reduction at the cathode and fuel oxidation at the anode. ${ }^{12}$ 


\subsection{References}

1. Singhal, S. C. \& Kendall, K. T. A.-T. T.-. High-temperature solid oxide fuel cells : fundamentals, design, and applicatons. (2003).

2. Schichlein, H., Müller, A. C., Voigts, M., Krügel, A. \& Ivers-Tiffée, E. Deconvolution of electrochemical impedance spectra for the identification of electrode reaction mechanisms in solid oxide fuel cells TT -. J. Appl. Electrochem. TA - 32, 875-882 (2002).

3. Leonide, A., Rüger, B., Weber, A., Meulenberg, W. A. \& Ivers-Tiffée, E. Impedance Study of Alternative ( $\mathrm{La}, \mathrm{Sr}) \mathrm{FeO}[\mathrm{sub} 3-\delta]$ and $(\mathrm{La}, \mathrm{Sr})(\mathrm{Co}, \mathrm{Fe}) \mathrm{O}[\mathrm{sub} 3-\delta] \mathrm{MIEC}$ Cathode Compositions TT -. J. Electrochem. Soc. TA - 157, B234 (2010).

4. A., L., V., S., A., W. \& E., I.-T. Evaluation and modeling of the cell resistance in anodesupported solid oxide fuel cells TT -. J. Electrochem. Soc. TA - 155, B36-B41 (2008).

5. Liu, B. et al. Analysis of Impedance Spectra for Segmented-in-Series Tubular Solid Oxide Fuel Cells TT -. J. Electrochem. Soc. TA - 157, B1858 (2010).

6. Finklea, H., Chen, X., Gerdes, K., Pakalapati, S. \& Celik, I. Analysis of SOFCs Using Reference Electrodes TT -. JOURNAL- Electrochem. Soc. TA - 160, F1055 (2013).

7. Kornely, M., Menzler, N. H., Weber, A. \& Ivers-Tiffée, E. Degradation of a High Performance SOFC Cathode by Cr-Poisoning at OCV-Conditions TT -. Fuel Cells TA - 13, 506-510 (2013).

8. Sonn, V., Leonide, A. \& Ivers-Tiffée, E. Combined Deconvolution and CNLS Fitting Approach Applied on the Impedance Response of Technical Ni/8YSZ Cermet Electrodes TT -. J. Electrochem. Soc. TA - 155, B675 (2008).

9. Brett, D. J. L., Atkinson, A., Brandon, N. P. \& Skinner, S. J. Intermediate temperature solid oxide fuel cells TT -. Chem. Soc. Rev. TA - 37, 1568-1578 (2008).

10. Zhang, X. et al. Enhanced oxygen reduction activity and solid oxide fuel cell performance with a nanoparticles-loaded cathode. TT -. Nano Lett. TA - 15, 1703-1709 (2015).

11. Almar, L., Szász, J., Weber, A. \& Ivers-Tiffée, E. Oxygen Transport Kinetics of Mixed lonicElectronic Conductors by Coupling Focused Ion Beam Tomography and Electrochemical Impedance Spectroscopy TT -. J. Electrochem. Soc. TA - 164, F289-F297 (2017).

12. Lee, K. T. \& Wachsman, E. D. Role of nanostructures on SOFC performance at reduced temperatures. MRS Bull. 39, 783-791 (2014). 


\section{Chapter 7: Effect of Electrode Modifications Analyzed by Distribution of Relaxation Times}

\subsection{Introduction}

Fuel cells are promising devices that provide abundant, stable, and clean energy. By electrochemically combining reactants, fuel cells produced electricity and avoid producing environmentally damaging pollutants. Recent efforts have been underway to lower the operating temperature of SOFCs in hope of avoiding expensive interconnection materials, long start up times, and increased performance derations. However, at lower operating temperatures the resistance from key processes increases.

Reduction of oxygen at the cathode is thermally activated, requires a high activation energy, and exhibits slow reaction kinetics. The process occurs as described in the following steps: oxygen gas diffuses though the porous framework, oxygen molecules adsorb to the electrode surface, adsorbed molecules dissociate into adsorbed atoms, oxygen atoms transport to the triple phase boundary, oxide ions form by electron transfer and incorporate into the electrolyte. ${ }^{1}$ The ORR contributed to the highest resistance and energy loss in SOFCs, especially at decreased operating temperatures. ${ }^{2}$ Surface modifications of SOFC have been widely employed on the electrodes to enhance catalytic properties and transportation of oxide ions. ${ }^{3}$

Elements of the DRT are not only functions of temperature and partial pressure but also depend on microstructure of the fuel cell. Distribution of relaxations times can further be applied to identify structural changes within a solid oxide fuel cell. Modifications to the electrode composition or structure will be reflected in the impedance spectrum. Because of the high resolution in distribution of relaxation times, electrochemical processes can be compared across cells.

\subsection{Methodology to Distribution of Relaxation Times}

In the present chapter, a commercially available anode supported SOFC (Materials and Systems Research, Inc.) was operated in an in-house test station at $750^{\circ} \mathrm{C}$. The cell consisted of a $0.9 \mathrm{~mm}$ thick Ni/YSZ (yttrium stabilized zirconia) support layer and a $15 \mu \mathrm{m} \mathrm{Ni}$ /YSZ active layer anode, a dense $12 \mu \mathrm{m}$ thick YSZ electrolyte, and a $15 \mu \mathrm{m}$ thick LSM/YSZ active layer and $50 \mu \mathrm{m}$ 
thick active layer cathode. The area of the anode and electrolyte were $3.5 \mathrm{~cm}^{2}$ while the cathode area was $2 \mathrm{~cm}^{2}$. A cell was modified though atomic layer deposition (ALD) to increase the density of triple phase boundaries in the cathode.

$\mathrm{H}_{2}$ was used at the fuel. Air was used to supply oxygen. The fuel and air streams were controlled via mass flow controllers. Cells were subjected to a constant current density of $0.3 \mathrm{~A} / \mathrm{cm}^{2}$. The cell impedance was collected with a potentiostat/galvanostat (Solartron 1289A) coupled with a frequency response analyzer (Solartron 1260). All impedance measurements were taken at open circuit conditions.

The impedance data was collected and the deconvolution of the impedance data was solved by Fourier transformation. ${ }^{4}$ The spectrum was recorded logarithmically with ten steps per decade from $100 \mathrm{kHz}$ to $0.05 \mathrm{~Hz}$. To reduce numerical errors in the Fourier transformation, the $Z^{\prime \prime}$ values should be close to zero at the high and low frequency limits. In practical measurements, only part of the spectrum is captured over a finite range; therefore, a linear regression was used to extend the endpoints of $Z^{\prime \prime}$ to values close to zero. This was performed under the assumption that only one physical process was active at the highest and lowest frequencies.

The extrapolated imaginary part of the impedance was transposed by Fast Fourier Transformation (FFT) and subsequently divided by the corresponding element of the transformed hyperbolic secant function. The transposed data was then subjected to a Hanning filter for noise removal. An inverse Fast Fourier Transformation of the filtered data yielded the desired deconvolution of relaxation times. Each deconvolution distribution was normalized and multiplied by its respective polarization resistance. This allowed for a comparison between different impedance measurements. Polarization resistance was determined by fitting the impedance data in the computer software ZView2. In the resulting plot of $g(f)$ vs log frequency, each peak corresponded to an individual physical phenomenon in the solid oxide fuel cell. To ascribe each peak to a physical process, the cell was subjected to tests where the operating parameters were systematically varied. By changing the operating conditions to purposefully effect one process in the fuel cell, the resulting DRT is altered to reflect such increase in resistance from the effected process. 


\subsection{Results of the Distribution of Relaxation Times}

Distribution of relaxation times plots consist of a series of peaks. Each peak in the curve corresponds to a physical phenomenon that the cell experiences while subjected to operation. Such physical origins include: diffusion in the cathode, diffusion in the anode, oxygen reduction reaction, and charge transfer reaction in the anode or cathode, and oxide ion transport though YSZ. The area under each peak reflects the resistance contribution from that process. Processes contributing the largest portion of resistance exhibit the highest peak intensity. The shape, height, and frequency of each peak are determined by the cell structure as well as operating conditions. When operating conditions are systematically altered, the effect on the physical processes within the fuel cell are shown as changes in each peak.

To observe the effects of temperature on the resistance of each process, the operating temperature was changed from $750^{\circ} \mathrm{C}$ to $700^{\circ} \mathrm{C}$. Also, the dependency of fuel concentration was analyzed by varying the hydrogen partial pressure in the anode gas stream. Figure 7.1 shows the distribution of relaxation times at two temperatures and two different hydrogen partial pressures. Hydrogen partial pressure was varied from $100 \%$ to $25 \%$ and balance with nitrogen. The cathode gas stream was kept constant in all four tests. The impedance measurements were taken at open circuit conditions. P1 shows a dependency on both temperature and hydrogen partial pressure. The magnitude of P1 increases with a decrease in temperature. P1 increases further in magnitude and shifts to $0.8 \mathrm{~Hz}$ upon decreasing hydrogen partial pressure. P2, P3, P4, and P5 all increase in magnitude with a decrease in temperature. Due to the strong dependency of P1 on hydrogen partial pressure, P1 can be ascribed to an anodic process. The frequency location for gas diffusion resistance in the anode (P1) in this study is in agreement with previously reported results. ${ }^{5}$ 


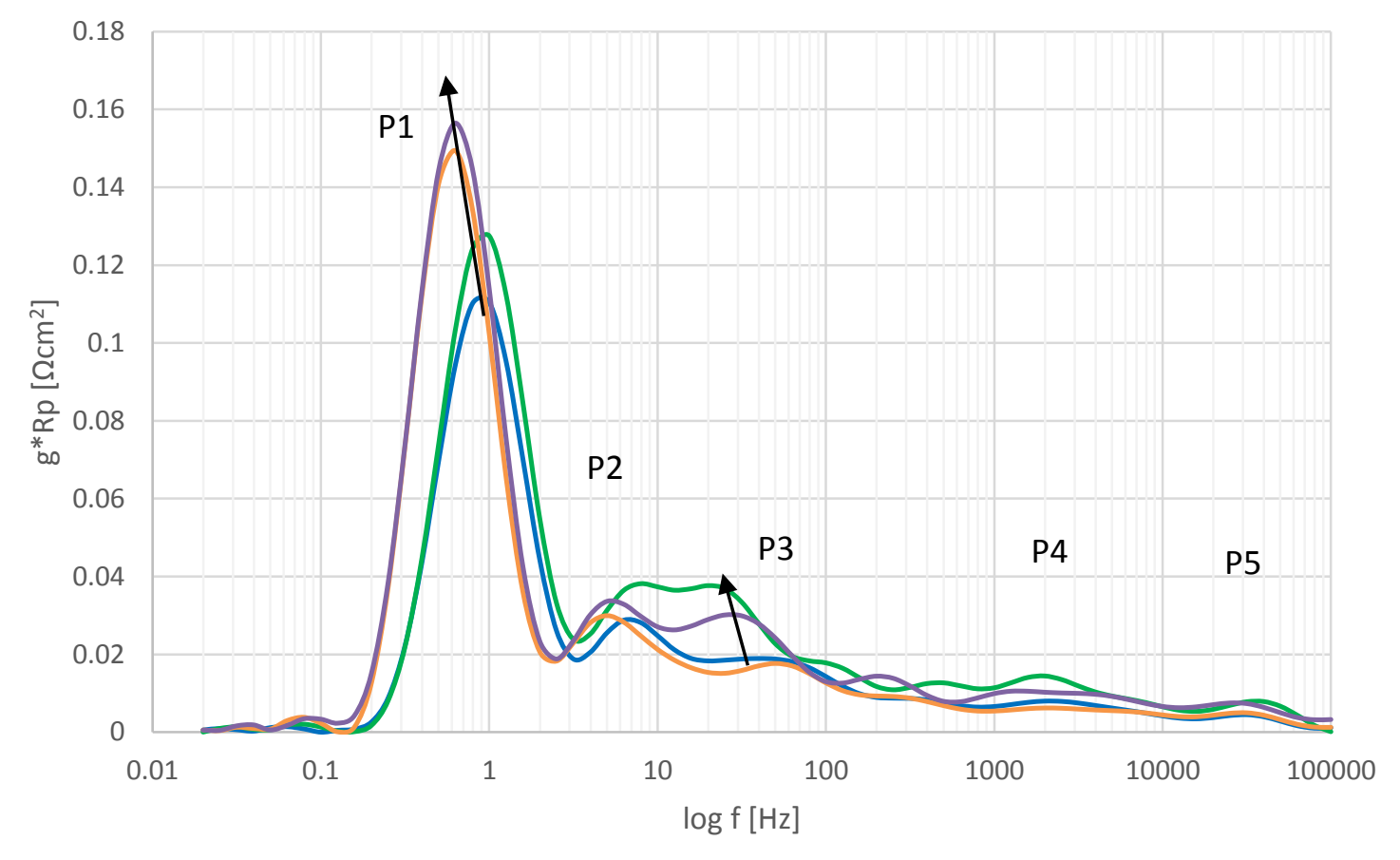

Figure 7.17. Distribution of relaxation times with varying hydrogen partial pressures measured at $750^{\circ} \mathrm{C}$ and $700^{\circ} \mathrm{C}$.

The dependency of oxygen partial pressure in the cathode gas composition was tested. Figure 7.2 shows the DRT plots at two temperatures, $750^{\circ} \mathrm{C}$ and $700^{\circ} \mathrm{C}$, and two different oxygen partial pressures, $20 \%$ and $5 \%$. Hydrogen partial pressure was held constant in all four tests. P1 show a dependency on both temperature and oxygen partial pressure. P1 increases with a decrease in temperature and further increases with a decrease in oxygen partial pressure. P2 arises only with low oxygen partial pressure. Due to the strong dependency on oxygen partial pressure, P2 can be ascribed as a cathodic process. P3, P4, P5 all increase with magnitude with a decrease in temperature. Charge transfer processes have been reported to have a little to no dependencies on oxygen partial pressure. ${ }^{6}$ Because P3, P4, and P5 had little dependency on cathode or anode partial pressures, these processes could be attributed to charge transfer limitations that occur between the current collect and electrode as well as the YSZ and LSM interfaces. 


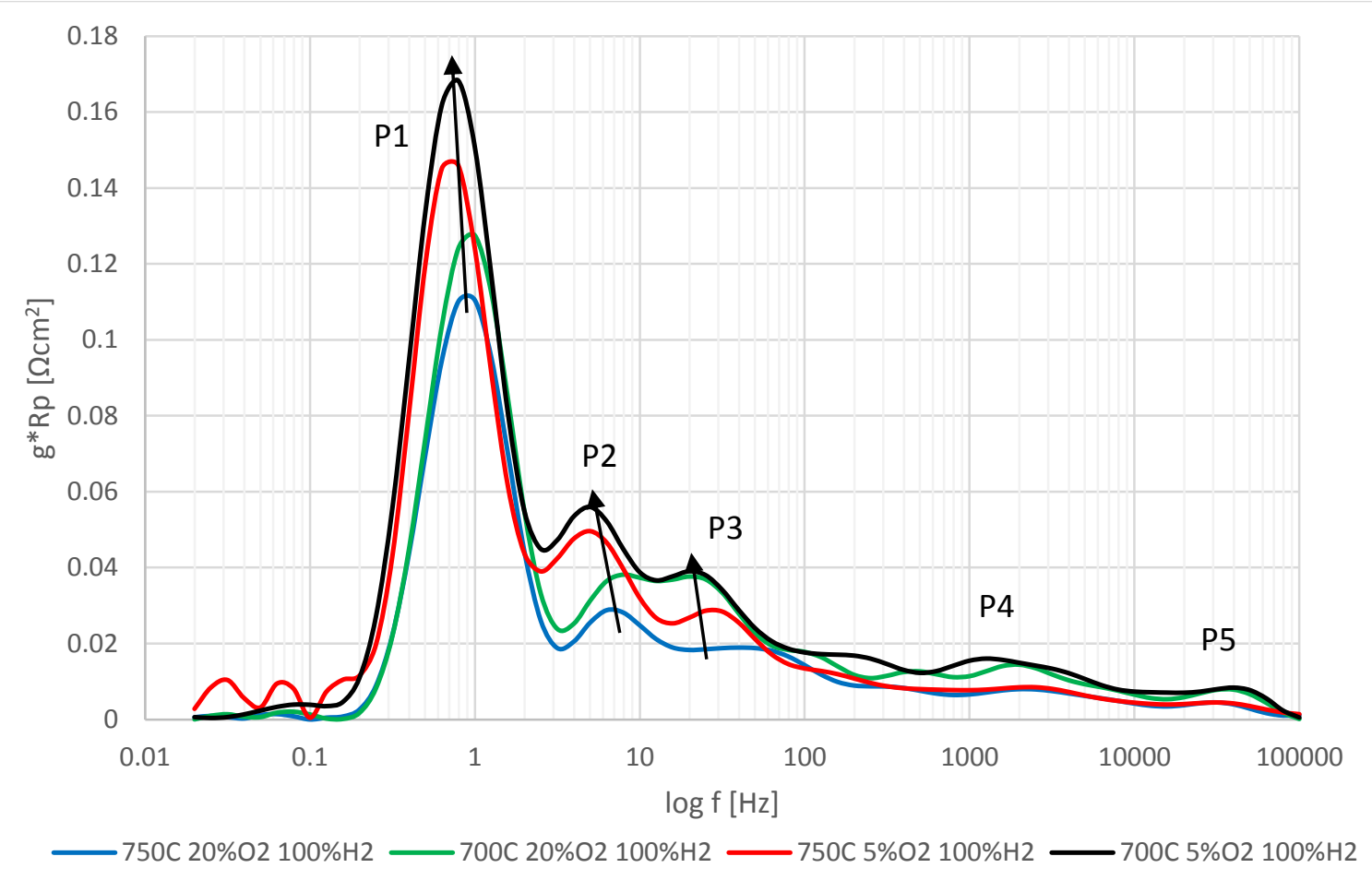

Figure 7.18. Distribution of relaxation times with varying oxygen partial pressure at $750^{\circ} \mathrm{C}$ and $700^{\circ} \mathrm{C}$.

Process 1 and process 2 both responded to changes in temperature and oxygen partial pressure. Both peaks are possibly related to electrochemical processes such as bulk diffusion and oxygen reduction reaction. The reduction of oxygen in the cathode is a function of chemical adsorption, surface transport, and electrode kinetics. Oxygen reduction reaction is a thermally activated process, and P1 exhibited a dependence on both temperature and the cathodic gas stream composition. P1 could depend on surface adsorption of oxygen and diffusion of oxygen though the cathode structure. P2 was also dependent on oxygen partial pressure and temperature. $\mathrm{P} 2$ could also be a function of oxygen reduction reaction at the triple phase boundary. The frequency corresponding to oxygen reduction reactions were previously reported to occur in a similar range. $^{7}$

Another indication that $\mathrm{P} 1$ and $\mathrm{P} 2$ are influenced by the cathode are their strong dependence on the cathode microstructure. Figure 7.3 below contains the deconvolution of 2 cells taken at the same operating conditions. Both cells were manufactured by MSRI. Because the peaks in the DRTs for both cells occur at the same frequencies, the same physical processes 
are contribution to those peaks. The modified cell was enhanced to increase the density of triple phase boundaries in the cathode. Oxygen reduction reaction is limited to close proximity to the triple phase boundary. Therefore, the increase in TPB would reduce the resistance from ORR. As mentioned, process 2 could be ascribed to the resistance from oxygen reduction reactions. The magnitude of $\mathrm{P} 2$ is higher for the baseline cell than for the modified cell. This reflects a reduction in resistance from the ORR in the modified sample which contains a higher density of TPBs.

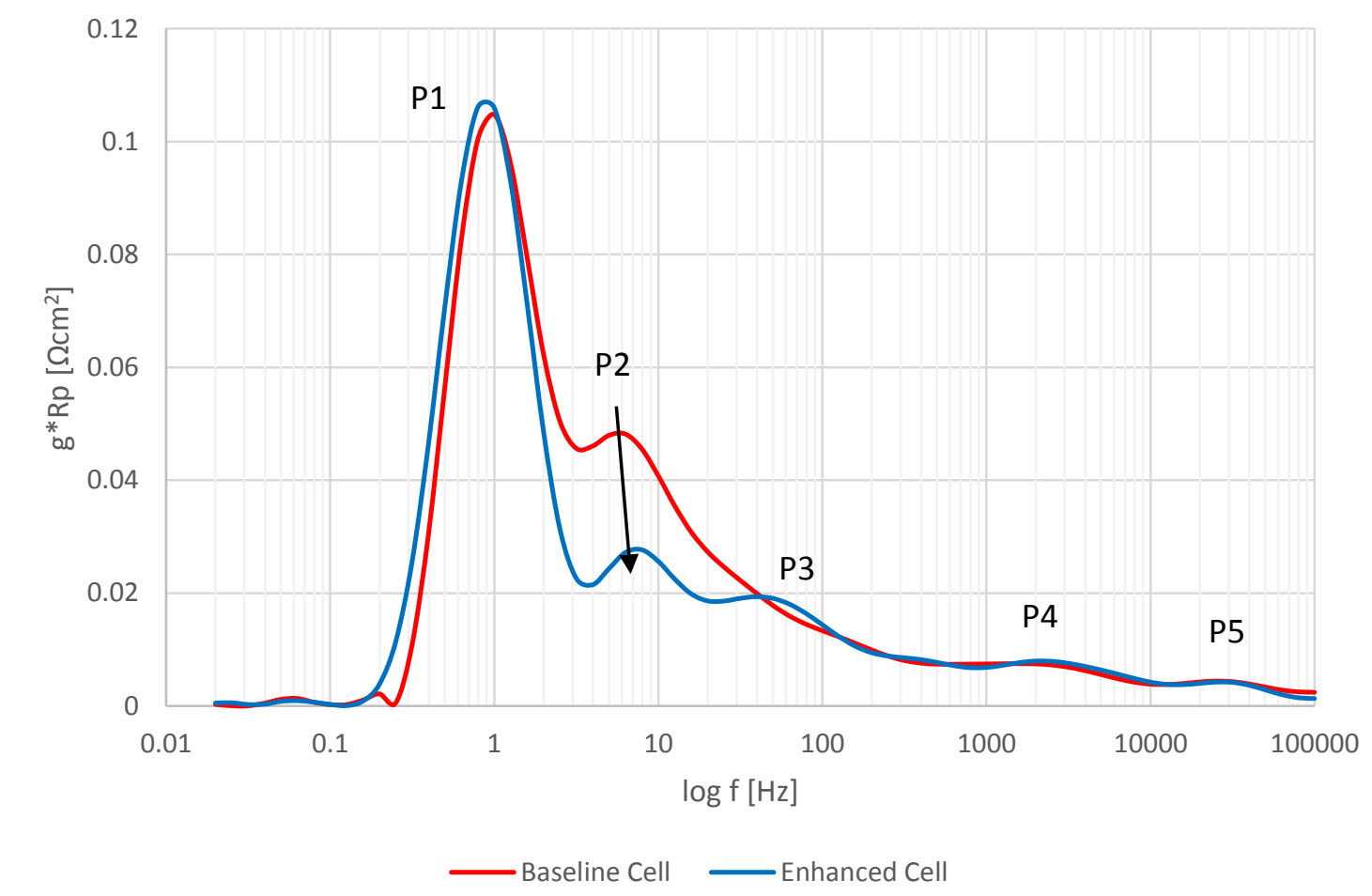

Figure 7.19. Comparison of DRT between baseline and modified cell with a higher density of TPB at OCV.

Upon subjecting the cell to cathodic overpotenial, an applied voltage serves as a driving force to reduce oxygen to ions at the triple phase boundary. The effects of activating the cathode material is reflected in the DRT in Figure 7.4. The enhanced cell also contains extended pathways for adsorbed oxygen to reach the triple phase boundary. The exhibited extended connections between the ionic and electronic phases that would reduce the resistance of oxygen surface exchange and surface diffusion as shown as a reduction in P1. Furthermore, a decrease in $\mathrm{P} 2$ reflects a reduction in resistance from the ORR in the modified sample which 
contains a higher density of TPBs. The high frequency processes were attributed to charge transfer limitations between phases. The increased contact between phases would increase the surface area for conducing pathways and thus reduce resistance between phases. This is reflected as a decrease in the magnitude of P3, P4, and P5.

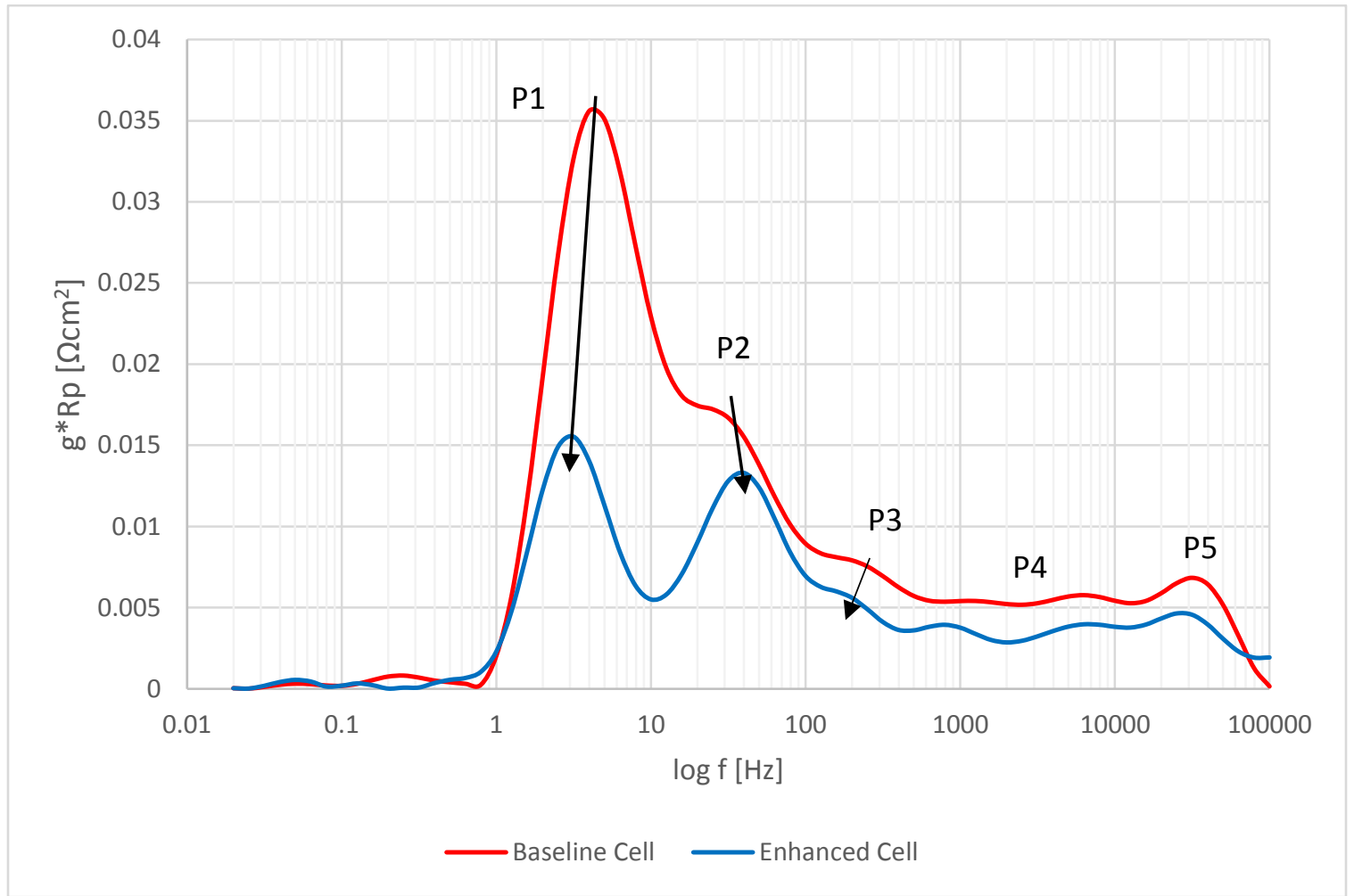

Figure 7.20. Comparison of DRT between baseline and modified cell with a higher density of TPB at an applied currrent of $0.3 \mathrm{~A} / \mathrm{cm}^{2}$.

\subsection{Summary of Results}

Distribution of relaxation times was applied to give insight into the electrochemical process of a modified cathode. Operating parameters were varied to determine the physical meaning of each peak. The peaks were then correlated to changes in the cathode structure. Peak 1 at $1 \mathrm{~Hz}$ was ascribed to gas diffusion in both the cathode and anode. P2 was ascribed to the oxygen reduction reaction. It was demonstrated that an increase in TPBs reduces the resistance from the ORR process. P3, P4, and P5 were ascribed to charge transfer between YSZ and LSM and the electrode and current collectors. The improved cell exhibited higher contact between ionic and electronic phases. This film reduced the resistance of charge transfer processes. 


\subsection{References}

1. Adler, S. B. Factors Governing Oxygen Reduction in Solid Oxide Fuel Cell Cathodes TT -. ChemInform TA - 35, no (2004).

2. Lee, K. T. \& Wachsman, E. D. Role of nanostructures on SOFC performance at reduced temperatures. MRS Bull. 39, 783-791 (2014).

3. Ding, D., Li, X., Lai, S. Y., Gerdes, K. \& Liu, M. Enhancing SOFC cathode performance by surface modification through infiltration. Energy Environ. Sci. 7, 552-575 (2014).

4. Finklea, H., Chen, X., Gerdes, K., Pakalapati, S. \& Celik, I. Analysis of SOFCs Using Reference Electrodes TT -. JOURNAL- Electrochem. Soc. TA - 160, F1055 (2013).

5. Liu, B. et al. Analysis of Impedance Spectra for Segmented-in-Series Tubular Solid Oxide Fuel Cells TT -. J. Electrochem. Soc. TA - 157, B1858 (2010).

6. Hayd, J. \& Ivers-Tiffee, E. Detailed Electrochemical Study on Nanoscaled La0.6Sr0.4CoO3- SOFC Thin-Film Cathodes in Dry, Humid and CO2-Containing Atmospheres TT -. J. Electrochem. Soc. TA - 160, F1197-F1206 (2013).

7. Leonide, A., Rüger, B., Weber, A., Meulenberg, W. A. \& Ivers-Tiffée, E. Impedance Study of Alternative (La,Sr)FeO[sub 3- $\delta$ ] and (La,Sr)(Co,Fe)O[sub 3- $\delta$ ] MIEC Cathode Compositions TT -. J. Electrochem. Soc. TA - 157, B234 (2010). 


\section{Chapter 8: Conclusion and Suggestions for Future Work}

\subsection{Conclusion}

This Master thesis encompassed the characterization and analysis of resistance from conductors and electrodes for solid oxide fuel cells. The Van der Pauw technique leveraged in this worked proved as an appropriate method to measure the conductivity of thin films. The application of thin films to increase oxygen ionic conductivity has been explored. The results showed that ionic conduction within nanostructured thin films exceeds that of conventional polycrystalline materials. Reducing the operating temperature of solid oxide fuel cells causes resistance from electrochemical processes to increase. The results in this work demonstrate that oxygen conducting thin films can be effective for application in solid oxide fuel cells to increase ionic conductivity at lower operating temperatures.

Solid oxide fuel cells are commonly measured though electrochemical impedance spectroscopy. In this thesis, a method to determine the distribution of relaxation times was applied to the impedance spectrum. In contrast to the spectrums obtained through electrochemical impedance spectroscopy where each electrochemical process overlaps, distribution of relaxation times resolves the impedance spectrum into a higher resolution plot where each individual process can be identified. While the cell was subjected to testing, operating parameters were varied to change the resistance corresponding to a specific processes. This allowed for the identification of each discrete process. Gas diffusion, oxygen reduction reaction, and charge transfer processes were identified. The resistance of the cell is a function of structure, temperature, and gas partial pressures. Gas diffusion through the bulk of the cathode and anode were dependent on oxygen and hydrogen partial pressures respectively. The oxygen reduction reaction was dependent on temperature, oxygen partial pressure, and the density of triple phase boundaries.

Reducing the polarizations of solid oxide fuel cells at lower temperatures remains a major focus of research. Recent strategies are aiming to tailor the surface structure and composition of the anode and cathode electrodes to further enhance their performance. By quantifying the resistance from each discrete process through distribution of relaxation times, 
the effectiveness of structural modifications on a single electrochemical process can be identified.

\subsection{Suggestions for Future Work}

It was shown that ionic conductivity is improved with the thin films of nanosize grains. The unique properties of nanostructured materials should be leveraged to increase the conductivity of solid oxide fuel cell electrodes at lower temperatures. Ionic conducting materials can be applied onto the electrodes as thin films to reduce the resistivity. The distribution of relaxation times provides substantially more information about electrochemical processes within the fuel cell than impedance spectrums. DRT can be used to model equivalent circuits of solid oxide fuel cells. The construction of equivalent circuits enables a quantitative value to be assigned to each physical process. 